\title{
Corophiidae (Crustacea, Amphipoda) da costa brasileira
}

\author{
Maria Teresa Valério-Berardo ${ }^{1}$ \\ Valter Kasuo Miyagi ${ }^{2}$
}

\begin{abstract}
Corophiidae (Crustacea, Amphipoda) from Brazilian coast. Twelve genera and seventeen species of corophiid amphipods are reported from Brazilian coastal waters: Ampelisciphotis podophthalma J.L. Barnard, 1958, Aora spinicornis Afonso, 1976, Audulla chelifera Chevreux, 1901, Bemlos foresti (Mateus \& Mateus, 1966), B. unicornis (Bynum \& Fox, 1977), Cheiriphotis megacheles (Giles, 1885), Chevalia mexicana Pearse, 1913, Corophium acherusicum Costa, 1851, Gammaropsis (Gammaropsis) atlantica Stebbing, 1888, G. (G.). thompsoni (Walker, 1898), G. (G.) togoensis (Schellenberg, 1925), G. (Podoceropsis) sophiae (Boeck, 1861), Globosolembos smithi (Holmes, 1905), Lembos hypacanthus (K.H. Barnard, 1916), Photis brevipes Shoemaker, 1942, P. longicaudata Bate \& Westwood, 1862 e Pseudomegamphopus barnardi Myers, 1968. An identification key, diagnosis and latitutinal distribution of each species are provided.
\end{abstract}

KEY WORDS. Amphipoda, Corophiidae, Brazilian coast

Os crustáceos da ordem Amphipoda constituem um grupo de ampla distribuição batimétrica e latitudinal, estando presentes em vários ecossistemas, do domínio pelagial ao bentônico. No Brasil, encontra-se poucos trabalhos taxonômicos baseados no grupo (OLIVEIRA 1951, 1953, 1954, 1955; WAKABARA \& LEITE 1977; BARNARD \& THOMAS 1988a,b: WAKABARA et al. 1988; SEREJO 1995, 1997).

Corophiidae é uma das famílias mais importantes da ordem Amphipoda. A abundância e diversidade de espécies têm sido amplamente destacada na literatura (BARNARD \& KARAMAN 1991). A revisão de gêneros foi feita por BARNARD (1973) e posteriormente por BARNARD \& KARAMAN (1991), representada por espécies que habitam desde a zona entremarés até o batial, particularmente com maior diversidade no sublitoral. Devido à controvérsia existente quanto à diagnose desta família, adotou-se a utilizada por BARNARD \& KARAMAN (1991) por incluir na sinonímia de Corophiidae as famílias Aoridae, Photidae e Isaeidae.

O registro de espécies de Amphipoda e da sua distribuição geográfica na costa brasileira foi feito por WAKABARA et al. (1991). O presente trabalho contribui para a ampliação de alguns dados de batimetria e latitude.

Este trabalho visa ampliar o conhecimento taxonômico da família, além de fornecer dados de sua ocorrência desde a região entremarés até a quebra da plataforma continental, facilitando a identificação das espécies registradas para a costa brasileira.

1) Faculdade de Ciências Biológicas, Exatas e Experimentais, Universidade Presbiteriana Mackenzie. Rua Itambé 135, 01239-902 São Paulo, São Paulo, Brasil.

2) Instituto Oceanográfico, Universidade de São Paulo. Caixa Postal 9075, 01065-970 São Paulo, São Paulo, Brasil. 


\section{MATERIAL E MÉTODOS}

A coleção das espécies de Corophiidae identificada neste estudo éproveniente de diversos projetos realizados em diferentes épocas, cedidos por vários coletores, entre as latitudes $7^{\circ}$ a $38^{\circ} \mathrm{S}$. As amostras da região entremarés foram coletadas manualmente e as de locais mais profundos foram obtidas através de dragas e pegadores.

As estruturas morfológicas mais importantes para a identificação das espécies são ilustradas. Para facilitar a identificação destas foi feita uma chave para os gêneros registrados na costa brasileira. Para gêneros com mais de uma espécie também foi apresentada uma chave para a sua identificação. A diagnose é dada para cada espécie, junto com o comprimento dos exemplares ilustrados. Este comprimento foi medido desde a base da antena 1 até a ponta do telso. Os exemplares destas espécies encontram-se depositados no Instituto Oceanográfico da Universidade de São Paulo.

\section{RESULTADOS}

Nesta coleção foram identificadas 17 espécies de Corophiidae, pertencentes a 12 gêneros. A distribuição batimétrica desta família na costa brasileira é registrada desde a região entremarés até $166 \mathrm{~m}$. As espécies com maiores distribuições batimétricas foram Ampelisciphotis podophthalma, Globosolembos smithi, Chevalia mexicana, Gammaropisis thompsoni, Photis brevipes e $P$. longicaudata, enquanto que Audulla chelifera, Lembos hypacanthus, Bemlos unicornis, Aora spinicornis e Gammaropsis atlantica, foram encontradas somente na região entremarés. Em relação aos dados de distribuição da família na costa brasileira, é importante destacar que a maioria dos exemplares examinados é proveniente de projetos com coletas abaixo de $18^{\circ} \mathrm{S}$. Nas latitudes inferiores a $13^{\circ} \mathrm{S}$ os espécimes são provenientes somente de coletas realizadas em região entre marés até 14 metros. Portanto, os registros de distribuição das espécies de Corophiidae não são conclusivos, pois não foi possivel até o momento, obter exemplares coletados em maiores profundidades na costa nordeste do Brasil. A espécie que apresentou maior distribuição latitudinal foi Photis longicaudata $\left(7^{\circ}-34^{\circ} \mathrm{S}\right)$.

\section{Diagnose da família}

Coxa 1 geralmente tão larga quanto a coxa 2, coxa 4 sem escavação posterior. Urossomitos 1-3 ou 1 e 2 às vezes coalescidos, mas nunca 2 e 3 coalescidos. Pedúnculo da antena $1 \mathrm{com}$ artículos 2-3 alongados. Gnatópodo 2 com artículo 3 curto. Pereópodo 5 mais longo que pereópodo 4 . Urópodo 3 com $0-2$ ramos, que, quando presentes são, em geral, mais longos que o pedúnculo e não apresentam espinhos articulados. Telso pequeno e inteiro (segundo BARNARD 1973).

As principais estruturas morfológicas para a classificação dos gêneros da família Corophiidae são: presença de flagelo acessório, gnatópodos 1 e 2 do macho, urossomitos, urópodos e telso. É importante destacar que a identificação de alguns gêneros como Aora Kroyer, 1845, Lembos Bate, 1856, Bemlos Shoemaker, 1925 e Globosolembos Myers, 1985 à nível específico é feita principalmente pelas características dos gnatópodos do macho, e portanto, a identificação de fêmeas isoladas é extremamente difícil (MYERS 1981). 


\section{Chave para os gêneros de Corophiidae}

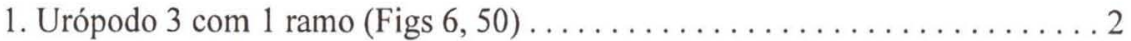

-. Urópodo 3 com 2 ramos, iguais ou não em comprimento (Figs 11,37 ) . . . . 3

2. Lobos laterais proeminentes (Fig. 1); artículo 7 dos pereópodos 3-5 com espinhos acessórios na margem interna (Figs. 4, 5) .......... Ampelisciphotis Lobos laterais não proeminentes, artículo 7 do pereópodo 4 normal . . Corophium 3. Urópodo $3 \mathrm{com}$ ramo interno bem menor que o externo (Figs. 37, 94, 101) . . 4

-. Urópodo 3 com ramos subiguais em comprimento (Figs.11, 17, 30) ......5

4. Artículo 3 da Antena 1 bem menor que 0 artículo 1; flagelo acessório multiarticulado (Fig. 34) ........................... Cheiriphotis

-. Artículo 3 da Antena 1 tão longo quanto o artículo 1; flagelo acessório ausente ou vestigial (Fig. 98) .............................. Photis

5. Gnatópodo 1 do macho mais robusto que o gnatópodo $2 \ldots \ldots \ldots \ldots \ldots 6$

- Gnatópodo 1 do macho menos robusto que o gnatópodo $2 \ldots \ldots \ldots \ldots \ldots$

6. Gnatópodo 1 do macho meroquelado (Fig. 9) ................ Aora

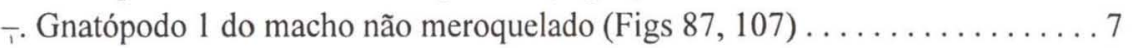

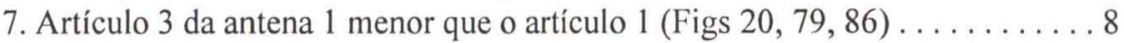

-. Artículo 3 da antena 1 subigual em comprimento ao artículo 1 (Fig. 106) ..... $\ldots \ldots \ldots \ldots \ldots \ldots \ldots \ldots \ldots \ldots \ldots \ldots \ldots \ldots \ldots$. Pseudomegamphopus

8. Artículo 5 do gnatópodo 1 igual ou maior que o artículo 6(Fig. 87) ..... Lembos -. Artículo 5 do gantópodo 1 menor que 0 artículo 6 (Figs 22, 28, 81) .....9

9. Gnatópodo 1 mais robusto que o gnatópodo 2, tanto no macho quanto na fêmea; artículo 6 sem dente ou protuberância intrapalmar (Fig. 81)...Globosolembos -. Gnatópodo 1 visivelmente mais robusto que o gnatópodo 2 somente no macho, artículo 6 com dente ou protuberância intrapalmar (Figs. 22, 28) . . Bemlos

10. Urossomitos 1 e 2 coalescidos (Fig. 42) ...................... Chevalia -. Urossomitos 1 e 2 não coalescidos . . . . . . . . . . . . . . . . . . . 11

11. Gnatópodo 2 paraquelado (Fig. 16) .................. Audulla -. Gnatópodo 2 quelado obliquamente (Figs. 54, 62, 69, 75) ...... Gammaropsis

\section{Ampelisciphotis podophthalma J.L. Barnard, 1958}

Figs 1-7

Ampelisciphotis podophthalma J.L. Barnard, 1958. Bull. S. Calif. Acad. Sci. 57: 85-90.

Diagnose do macho $(4,8 \mathrm{~mm})$. Cabeça com lobo lateral pronunciado, formando um pedúnculo, com o olho na extremidade. Gnatópodo $1 \mathrm{com}$ palma oblíqua. Palma do gnatópodo 2 definida por um espinho. Pereópodos 3, 4 e 5 com artículo 7 trifurcado. Urópodo $3 \mathrm{com}$ um só ramo mais curto que o pedúnculo. Telso triangular. Diagnose da fêmea $(5,0 \mathrm{~mm})$. Esta espécie não apresenta dimorfismo sexual evidente.

Distribuição batimétrica e latitudinal. Na costa brasileira esta espécie foi coletada em profundidades de 2 a 117 metros em substrato arenoso, lodo e cascalho. Distribuída na costa leste-sul (18 $\left.44^{\prime} \mathrm{S}-34^{\circ} 34^{\prime} \mathrm{S}\right)$. 


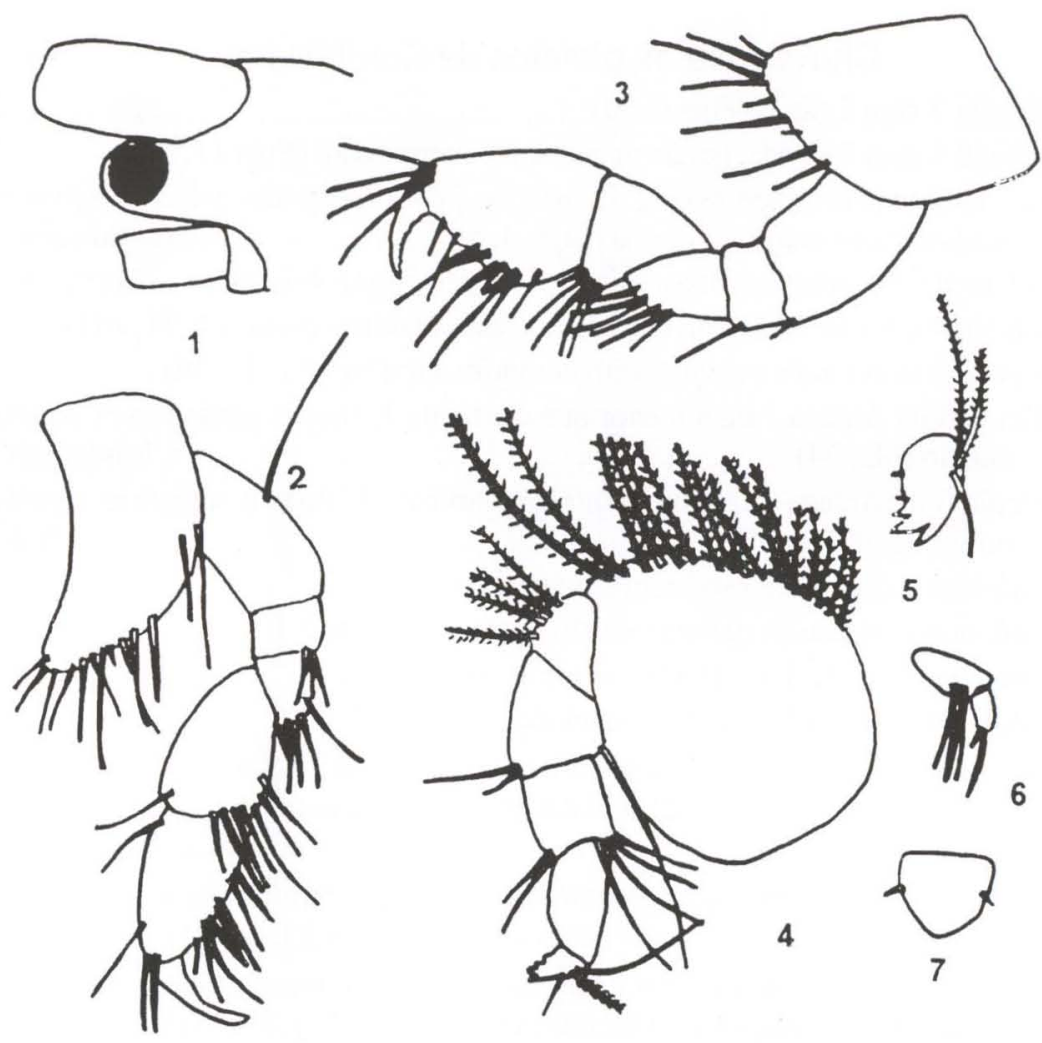

Figs 1-7. Ampelisciphotis podophthalma. (1-7) Macho: (1) detalhe da cabeça; (2) gnatópodo 1 ; (3) gnatópodo 2; (4) pereópodo 3; (5) detalhe do artículo 7 do pereópodo 3; (6) urópodo 3; (7) telso.

\section{Aora spinicornis Afonso, 1976}

Figs 8-13

Aora gracilis Della Valle, 1893. Fauna und Flora des Golfes von Neapel und des angrenzenden Meers-Abschnitte. Monographie 20: XI+948p.

Aora atlantidea Myers, 1973. Mem. Mus. Civ. Stor. nat., Verona, 20: 283-302.

Aora spinicornis Afonso, 1976. Publ. Inst. Zool. "Dr Augusto Nobre" 135: 11-32. - Ruffo, 1982.

Mem. L'Inst. Oceanogr. 13: 1-364.

Diagnose do macho. $(6,9 \mathrm{~mm})$ Flagelo acessório multi-articulado. Gnatópodo 1 mais desenvolvido que gnatópodo 2, carpoquelado, densamente cerdoso nos artículos 5 e 6 . Gnatópodo 2 com artículo 6 subigual ao artículo 5, palma transversa. Urópodo 3 com ramos ligeiramente maiores que o pedúnculo, com cerdas terminais. Telso com dois pares de cerdas na margem distal.

Diagnose da fêmea $(6,4 \mathrm{~mm})$. Gnatópodo 1 não carpoquelado, artículo 6 mais longo que o 5, palma oblíqua, definida por um espinho. Gnatópodo 2 com artículo 6 maior que o 5 , palma oblíqua. 
Distribuição batimétrica e latitudinal. Exemplares encontrados em regiões entremarés, entre algas e lodo. Sua distribuição latitudinal registrada é de $23^{\circ} 30^{\prime}$ $23^{\circ} 48^{\prime} \mathrm{S}$.

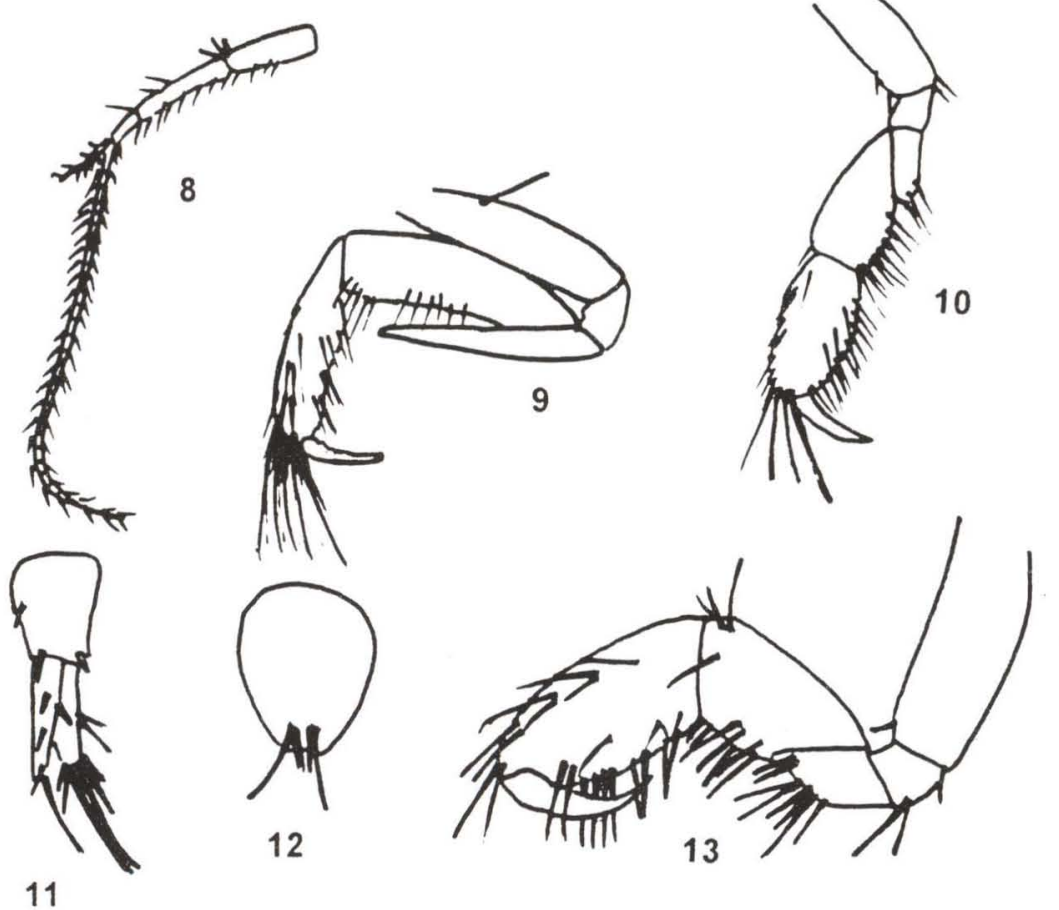

Figs 8-13. Aora spinicornis, macho. (8) Antena 1; (9) gnatópodo 1; (10) gnatópodo 2; (11) urópodo 3; (12) telso. (13) Fêmea: gnatópodo 1.

\section{Audulla chelifera Chevreux, 1901}

\section{Figs 14-19}

Audulla chelifera Chevreux, 1901. Mem. Soc. Zool. Fr. 14: 388-438. - Thomas \& Barnard, 1987. Proc. biol. Soc. Wash. 100: 364-370.

Eurystheus lina Kunkel, 1910. Trans. Conn. Acad. Arts Sci. 16: 1-116.

Eurystheus semichelatus K.H. Barnard, 1957. Ann. Mag. Nat. Hist., Ser. (12) 10: 1-12.

Gammaropsis cheliferus; Ruffo, 1969. Mém. Inst. Oceanogr. 13: 1-360.

Gammaropsis chelifera; Ledoyer, 1972. Tethys, Supp. 3: 165-286.

Diagnose do macho $(5,4 \mathrm{~mm})$. Cabeça sem lobos laterais proeminentes. Antena 1 com flagelo acessório 4-articulado. Gnatópodo 1 com palma oblíqua, artículo 7 serrilhado na margem interna. Gnatópodo 2 bem mais volumoso que gnatópodo 1, artículo 6 volumoso e ovóide, com cerdas na margem ventral, apresentando ainda uma projeção triangular póstero-distal ocupando toda a palma e que juntamente com o artículo 7, dá ao gnatópodo 2 um aspecto quelado. Urópodo 3 birreme, com espinhos no pedúnculo e ramos. Telso com um par de espinhos na margem distal. 
Diagnose da fêmea (4,8mm). Gnatópodo 2 bem menos desenvolvido que o do macho, palma oblíqua, sem a projeção triangular e definida por um espinho.

Distribuição batimétrica e latitudinal. Esta espécie ocorre em região entremarés, associada a algas, entre as latitudes $20^{\circ} 41^{\prime}-29^{\circ} 19^{\prime} \mathrm{S}$.

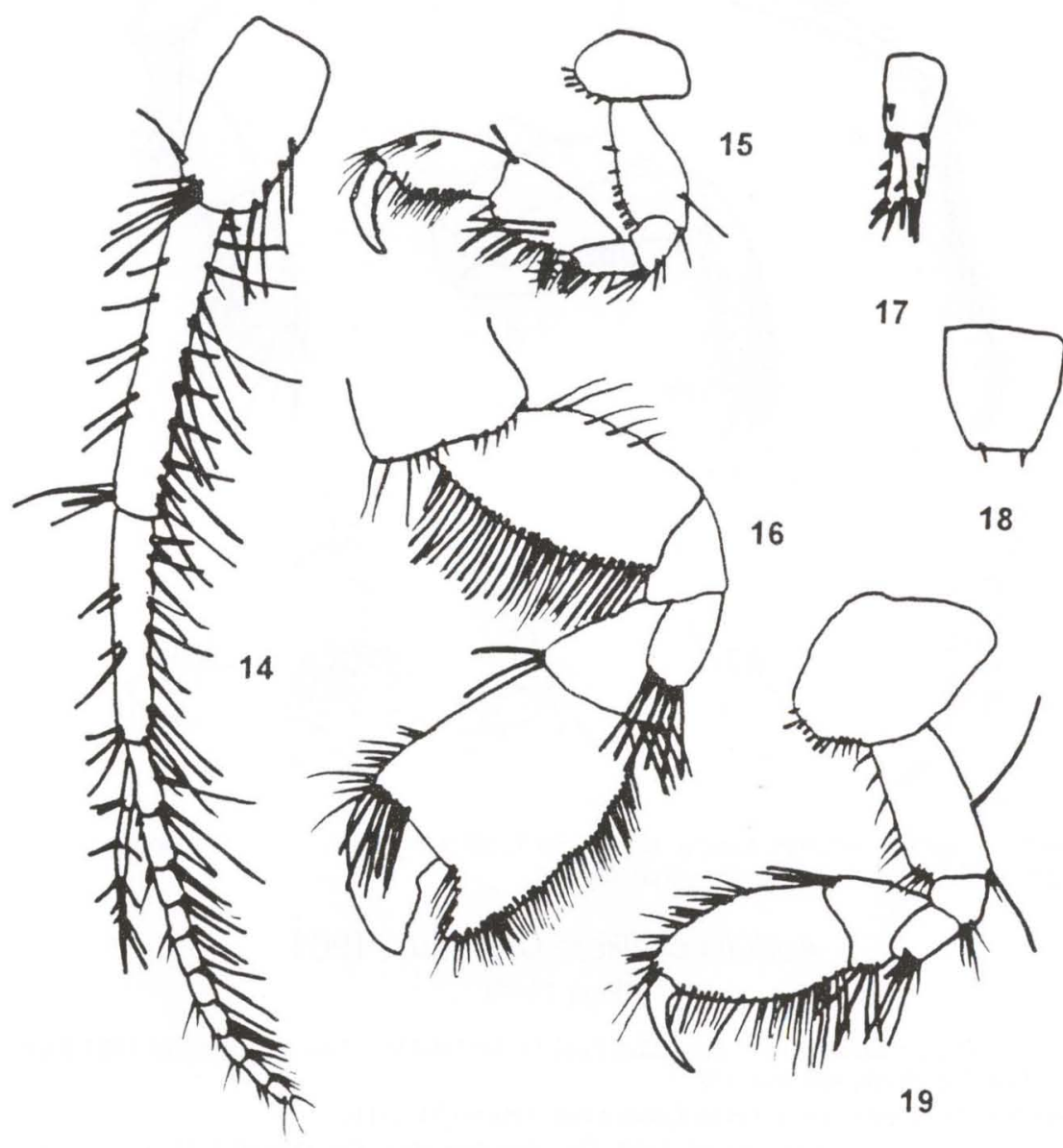

Figs 14-19. Audulla chelifera. (14-19) Macho: (14) antena 1; (15) gnatópodo 1; (16) gnatópodo 2; (17) urópodo 3; (18) telso. (19) Fêmea: gnatópodo 2.

\section{Chave para as espécies do gênero Bemlos}

1. Palma do gnatópodo 1 do macho com um dente afilado sem espinho (Fig. 22); gnatópodo 2 com margem superior dos artículos 5 e 6 pobremente cerdosa (Fig. 23) . . . . . . f . foresti

-. Palma do gnatópodo 1 do macho definida por um dente arredondado seguido por um espinho (Fig. 28); gnatópodo 2 do macho com margem superior dos artículos 5 e 6 densamente cerdosa (Fig. 29) ............. unicornis 


\section{Bemlos foresti (Mateus \& Mateus, 1966)}

Figs 20-27

Lembos foresti Mateus \& Mateus, 1966. Ann. L'Inst. Oceanogr., Paris, 44: 173-198.

Bemlos foresti; Myers, 1978. Boll. Mus. Civ. Stor. nat., Verona, 5: 183-209.

Diagnose do macho $(7,0 \mathrm{~mm})$. Flagelo acessório multi-articulado. Antena 2 com metade do comprimento da antena 1, mas de aparência mais robusta. Gnatópodo 1 mais robusto que o gnatópodo 2, artículo 6 com bordo da palma transversa, definida por um dente seguido de uma profunda depressão e junto à articulação da palma, margem crenulada, artículo 7 mais longo que a palma. Gnatópodo 2, com palma oblíqua definida por um espinho. Urópodo 3 com ramos subiguais em comprimento e mais longos que o pedúnculo. Telso com 2 pares de cerdas na margem posterior.

Diagnose da fềmea $(6,7 \mathrm{~mm})$. Gnatópodo $1 \mathrm{com}$ palma oblíqua definida por um forte dente. Gnatópodo 2 com palma oblíqua, artículo 7 mais longo que a palma.

Distribuição batimétrica e latitudinal. Esta espécie foi coletada em profundidade de 75 metros, em areia, na latitude $23^{\circ} 30^{\prime}$ S.

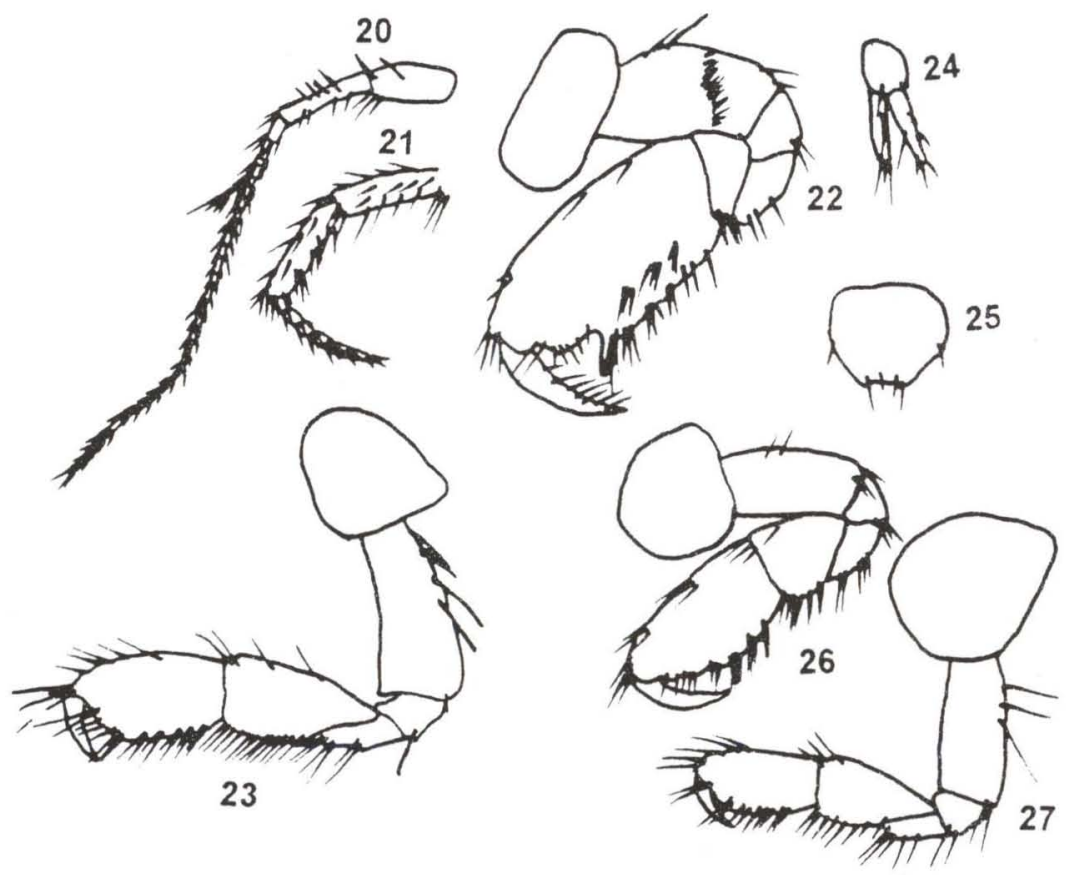

Figs 20-27. Bemlos foresti. (20-25) Macho: (20) antena $1 ;(21)$ antena 2; (22) gnatópodo 1; (23) gnatópodo 2; (24) urópodo 3; (25) telso. (26-27) Fêmea: (26) gnatópodo 1; (27) gnatópodo 2. 


\section{Bemlos unicornis (Bynum \& Fox, 1977)}

Figs 28-33

Lembos unicornis Bynun \& Fox, 1977. Chesapeake Sei. 18 (1): 1-33.

Bemlos unicornis; Myers, 1977. Boll. Mus. Civ. Stor. nat., Verona, 4: 133-152.

Diagnose do macho $(5,6 \mathrm{~mm})$. Gnatópodo 1 com artículo 2 robusto, artículo 6 grande e oval, com margem dorsal cerdosa, apenas distalmente, palma com uma protuberância retangular perto da articulação com o artículo 7, seguida de uma reentrância arredondada, definida por um grande dente e pequeno espinho. Gnatópodo 2, artículo 2 com margem dorso-distal formando um ângulo reto bem definido, artículos 4 e 5 densamente cerdosos nas margens, artículo 6 menor que o artículo 5, palma transversa. Ramos do urópodo $3 \mathrm{com}$ longas cerdas terminais. Telso com margem distal com uma pequena reentrância arredondada com cerdas terminais.

Diagnose da fêmea $(4,0 \mathrm{~mm})$. Difere do macho pelos gnatópodos. Gnatópodo 1 menos robusto, palma oblíqua, serrilhada, definida por um espinho. Gnatópodo 2 com palma transversa definida por um espinho, artículo 7 com margem interna provida de 5 pequenos dentes.

Considerações. Nossos exemplares não apresentaram antena 1 e 2 e também os pereópodos 3 a 7. A identificação baseou-se nos gnatópodos do macho e fêmea, urópodos e telso.

Distribuição batimétrica e latitudinal. Esta espécie foi coletada em regiões entremarés, entre algas, na costa nordeste do Brasil ( $\left.7^{\circ} 45^{\prime}-9^{\circ} 42^{\prime} \mathrm{S}\right)$.

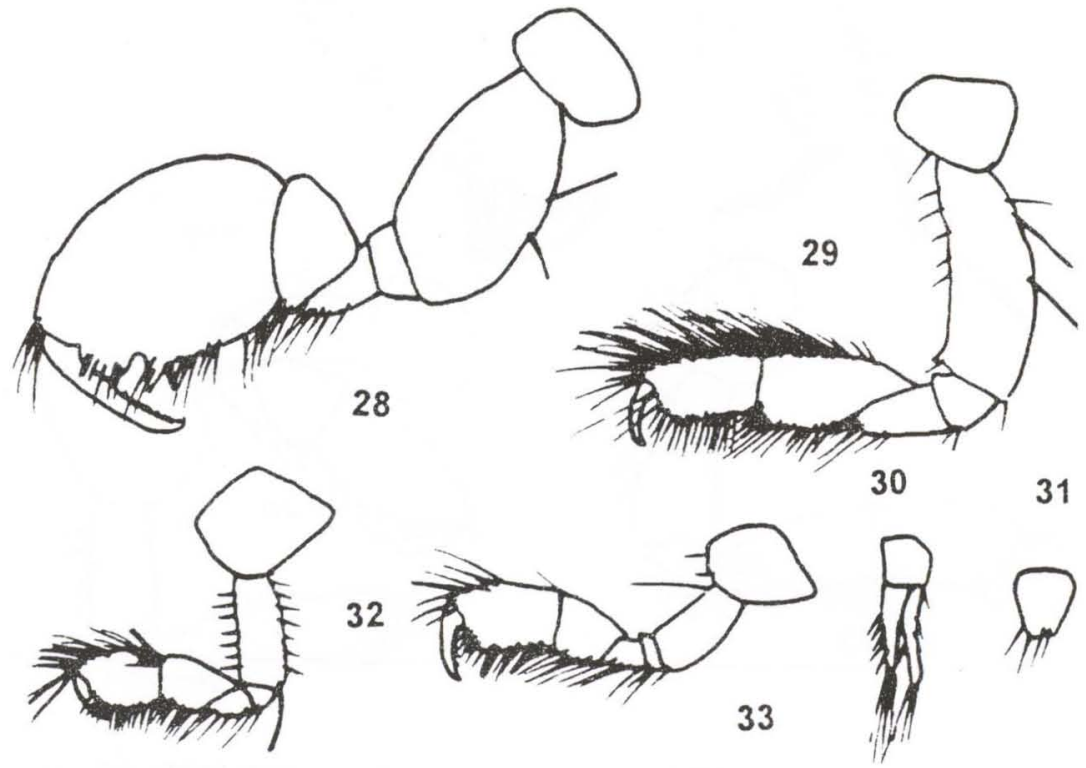

Figs 28-33. Bemlos unicornis. (28-31) Macho: (28) gnatópodo 1; (29) gnatópodo 2; (30) urópodo 3; (31) telso. (32-33) Fêmea: (32) gnatópodo 1; (33) gnatópodo 2. 


\section{Cheiriphotis megacheles (Giles, 1885)}

Figs $34-40$

Eurystheus megacheles Giles, 1885. Jour. Asiatic. Soc. Bengal 54: 69-71.

Eurystheus monuropus Walker, 1909. Trans. Linn. Soc. Lond., ser. 2, Zool. 12: 343-344.

Cheiriphotis durbanensis K.H. Barnard, 1916. Ann. S. Afr. Mus. 15: 105- 302.

Cheiriphotis walker Stebbing, 1918. Ann Durbam Mus. 2: 47-75.

Cheiriphotis delloyei Pirlot, 1934. Siboga Exped. Mon. 33e: 237-328.

Cheiriphotis megacheles K.H. Barnard, 1937. Scient. Rep. John Murray Exped. 4: 131-201. - J.L. Barnard, 1962. Pacif. Nat. 3: 1-72.

Diagnose do macho $(5,2 \mathrm{~mm})$. Flagelo acessório 3-articulado. Coxas 1 a 4 desenvolvidas, com cerdas na margem ventral. Gnatópodo 1 menos desenvolvido que o gnatópodo 2, com palma oblíqua, com artículo 7 maior que a palma. Gnatópodo 2 bem desenvolvido, artículo 6 robusto de forma oval, margem ventral muito reduzida em adultos, palma longa, oblíqua, com um dente largo na região próxima à articulação com o dáctilo; artículo 7 bem desenvolvido, com margem lisa. Urópodo $3 \mathrm{com}$ ramo interno bem menor que o externo.

Diagnose da fêmea $(4,0 \mathrm{~mm})$. Difere do macho pelos gnatópodos. Gnatópodo 1 menos robusto, palma oblíqua, serrilhada, definida por um espinho. Gnatópodo 2 com palma transversa definida por um espinho, artículo 7 com margem interna provida de 5 pequenos dentes.

Considerações. Esta espécie apresenta uma ampla variação morfológica em relação ao gnatópodo 2 do macho e ao urópodo 3 .

Distribuição batimétrica e latitudinal. Esta espécie foi coletada em regiões entremarés, entre algas, até a profundidade de 44 metros entre as latitudes $7^{\circ} 45^{\prime}$ $23^{\circ} 48^{\prime} \mathrm{S}$.

\section{Chevalia mexicana Pearse, 1913}

Figs 41-46

Chevalia mexicana Pearse, 1913. Proc. U.S. Nat. Mus. 43: 369-379.

Chevalia aviculae Shoemaker, 1921. Univ. Iowa Stud. Nat. Hist. 9: 99-102. - Ledoyer, 1982. Faune de Madagascar 59: 598.

Diagnose do macho (4,0mm). Flagelo acessório 2 articulado, sendo o artículo 2 rudimentar. Coxas pouco desenvolvidas, descontínuas. Pleonitos 4 e 5 coalescidos. Gnatópodo 1 de aspecto delgado, com palma oblíqua. Gnatópodo 2 robusto, palma transversa definida por uma projeção junto com um espinho. Pereópodos 3 , 4 e 5 com artículo 7 de forma curvada, bífide em forma de gancho, característico da espécie. Urópodo 3 pequeno, ramos tão longos quanto o pedúnculo, com cerdas terminais. Telso de forma quadrada, apresentando 2 tufos de 3 cerdas na margem distal.

Diagnose da fềmea. Esta espécie não apresenta dimorfismo sexual.

Distribuição batimétrica e latitudinal. Exemplares examinados foram coletados em profundidades de 0 a 132 metros, entre algas e em sedimento variado, com ampla distribuição latitudinal na costa brasileira ( $\left.7^{\circ} 45^{\prime}-23^{\circ} 19^{\prime} \mathrm{S}\right)$. 

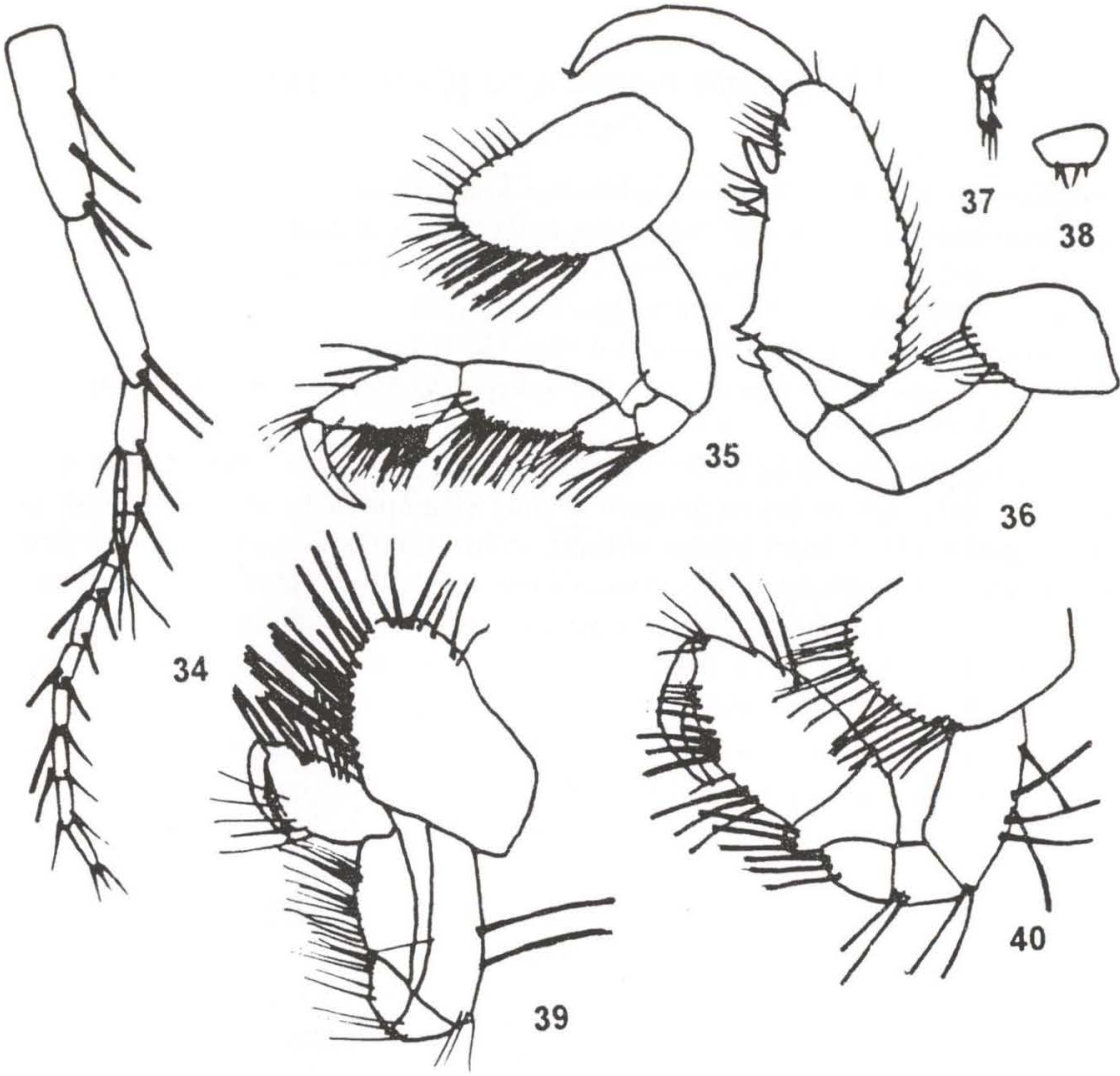

Figs 34-40. Cheiriphotis megacheles. (34-38) Macho: (34) antena 1; (35) gnatópodo 1; (36) gnatópodo 2; (37) urópodo 3; (38) telso. (39-40) Fêmea: (39) gnatópodo 1; (40) gnatópodo 2.

\section{Corophium acherusicum Costa, 1851}

\section{Figs 47-51}

Corophium acherusicum Costa, 1851. Fr. Gugl. Hope. Napoli: 1-48. -Stebbing, 1906. Das Tiereich 21: 1-806. - Fox \& Bynum, 1975. Ches. Sci. 16 (4): 223-237. - Hirayama, 1984. Publs Seto mar. Biol. Lab. 29 (173): 1-92.

Diagnose do macho $(3,3 \mathrm{~mm})$. Antena 2 mais robusta que a antena 1 , artículo 4 com o comprimento aproximadamente 2,5 da largura com margem ventro-distal com 2 dentes seguidos por uma fenda, artículo 5 com um pequeno processo na margem proximal, que se encaixa entre os dentes do artículo 4 , com uma projeção triangular na margem distal. Gnatópodo 1 com densa cerdação nas margens ventrais dos artículos 3, 4 e 5, artículo 7 excedendo a palma. Gnatópodo 2 com densa cerdação na margem ventral dos artículos 4 e 5, artículo 7 com dentes na margem interna. Segmentos do urossomo coalescidos. Urópodo 3 unirreme, com ramo mais longo que o pedúnculo e arredondado, com cerdas nas margens. Telso com margem arredondada, com ligeira reentrância distal, apresentando um espinho de cada lado.

Diagnose da fềmea $(3,8 \mathrm{~mm})$. Difere do macho pelo menor desenvolvimento das antenas, principalmente as antenas 2 . 
Dsitribuição batimétrica e latitudinal. Esta espécie é encontrada em águas rasas até $48 \mathrm{~m}$, principalmente em regiões calmas e estuarinas, construindo tubos de grãos de sedimento ou detritos, em objetos submersos, entre algas, tunicados, briozoários, etc. Na costa brasileira foi registrada entre as latitudes de $7^{\circ} 45^{\prime}-24^{\circ} 55^{\prime} \mathrm{S}$.

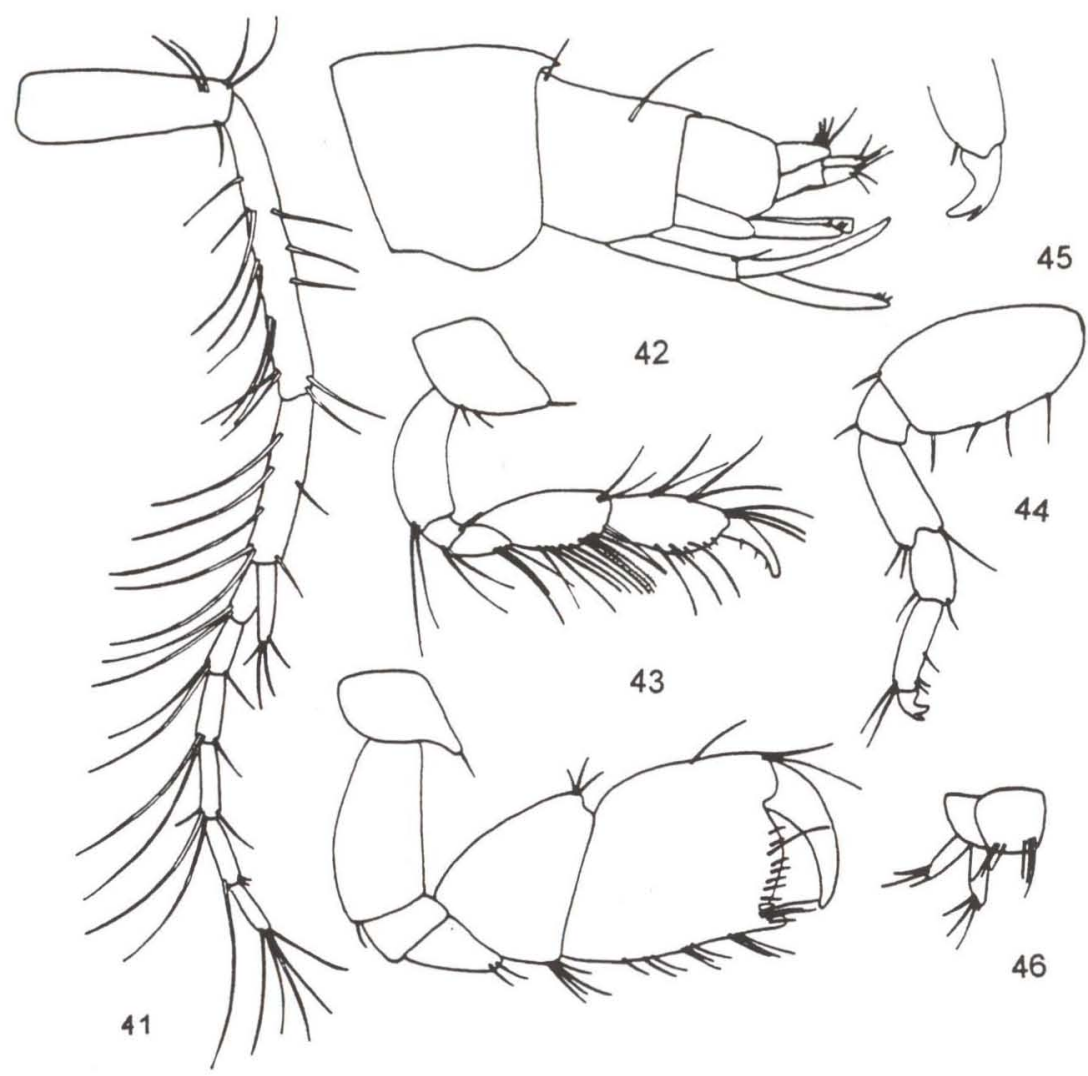

Figs 41-46. Chevalia mexicana, macho. (41) Antena 1; (42) pleonitos 4-6; (43) gnatópodo 1; (44) gnatópodo 2 ; (45) pereópodo 3 com detalhe do artículo 7; (46) urópodo 3 e telso.

Chave para as espécies do gênero Gammaropsis

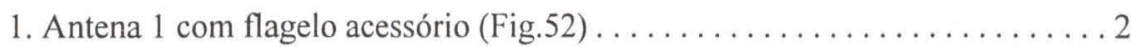
-. Antena 1 sem flagelo acessório (Fig. 73) ......... G. (Podocerospsis) sophiae

2. Urópodo 3 com ramo externo mais robusto que o interno (Figs 56,71 ) . . . . 3

-. Urópodo 3 com ramos iguais (Fig. 64) ......... (Gammaropsis) thompsoni

3. Gnatópodo 2 com palma transversa (Fig. 54), cabeça sem lobos laterais proeminentes .............................. (Gammaropsis) atlantica

-. Gnatópodo 2 com palma oblíqua (Fig. 70), cabeça com lobos laterais proeminentes (Fig. 68) ....................... G. (Gammaropsis) togoensis 

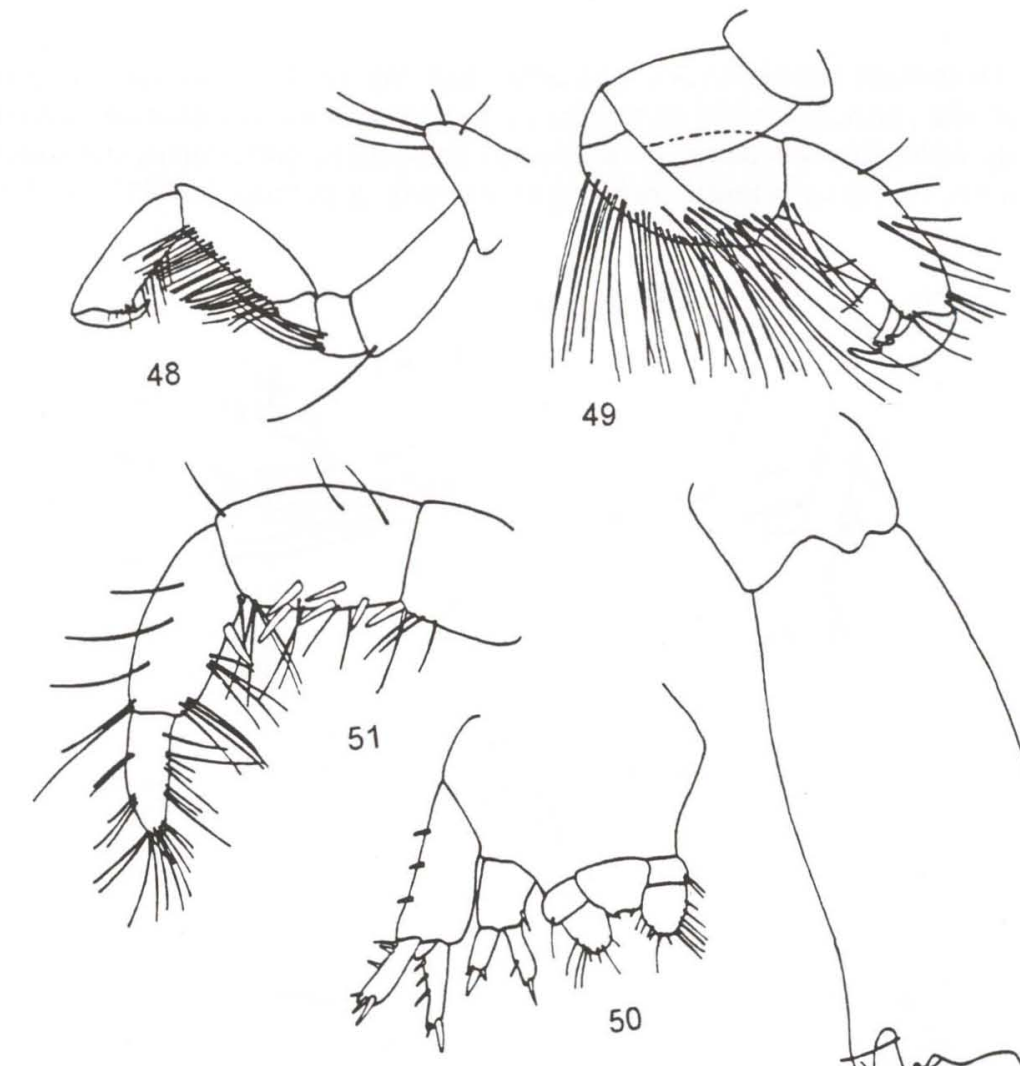

49
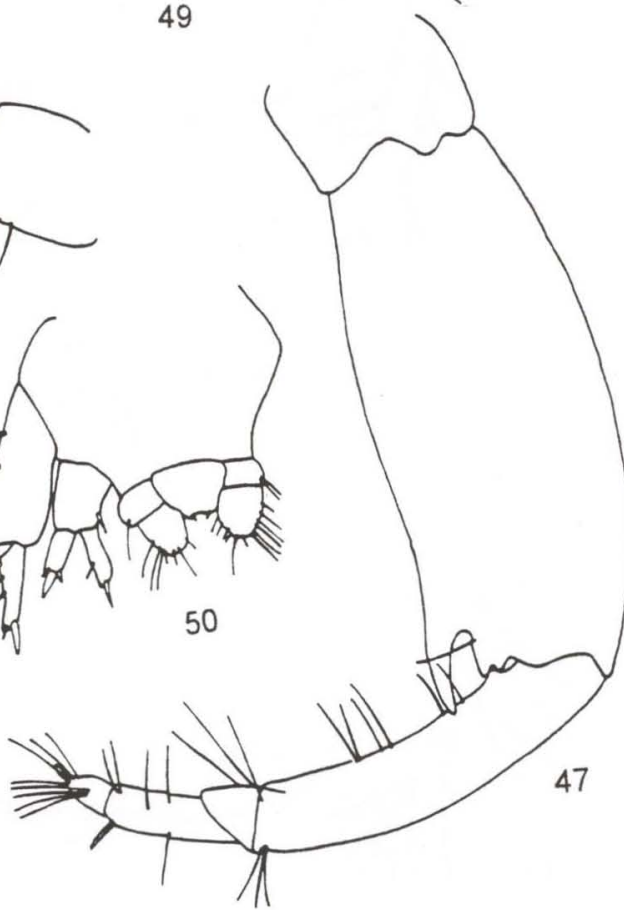

Figs 47-51. Corophium acherusicum, macho: (47) antena 2, (48) gnatópodo 1, (49) gnatópodo 2, (50) urossomo; fêmea: (51) antena 2.

\section{Gammaropsis (Gammaropsis) atlantica Stebbing, 1888 Figs $52-58$}

Gammaropsis atlantica Stebbing, 1888. Report Scientif Results Voyage of H.M.S. Challenger during the Years 1873-1876, Zoology 29: XXIV+1737p.. - J.L. Barnard, 1970. Smiths. Contrib. Zool. 34: 1-286.

Gammaropsis zeylanicus Walker, 1904. Report to the Goverment of Ceylon on the Pearl Oyters Fisheries of the Gulf of Manaar, Supplementary Report 17: 229-300.

Gammaropsis gardineri Walker, 1905. Fauna and Geography of the Maldive and Laccadive Archipelagoes 2, Suppl. 1: 923-932.

Eurystheus atlanticus; Stebbing, 1906. Das Tierreich 21: 1-806p. 
Diagnose do macho. (5,0mm) Flagelo acessório 6-articulado. Antena 1 e 2 subiguais em comprimento. Gnatópodo 1 menos robusto que o gnatópodo 2, com palma oblíqua. Gnatópodo 2 com artículo 6 massivo, palma transversa, margem palmar com uma protuberância seguida por uma reetrância irregular, com margem definida por uma dente. Urópodo 1 com um processo entre os ramos. Urópodo 3, com ramos subiguais em comprimento, ramo interno mais delgado que o externo. Telso com margem póstero-lateral com 2 pares de espinhos e 1 cerda.

Diagnose da fêmea $(4,5 \mathrm{~mm})$. Gnatópodo 2 menos robusto, palma oblíqua definida por um pequeno dente.

Distribuição batimétrica e latitudinal. Esta espécie foi coletada entre algas na região entremarés na latitude de $24^{\circ} 12^{\prime}-46^{\circ} 47^{\prime} \mathrm{W}$.

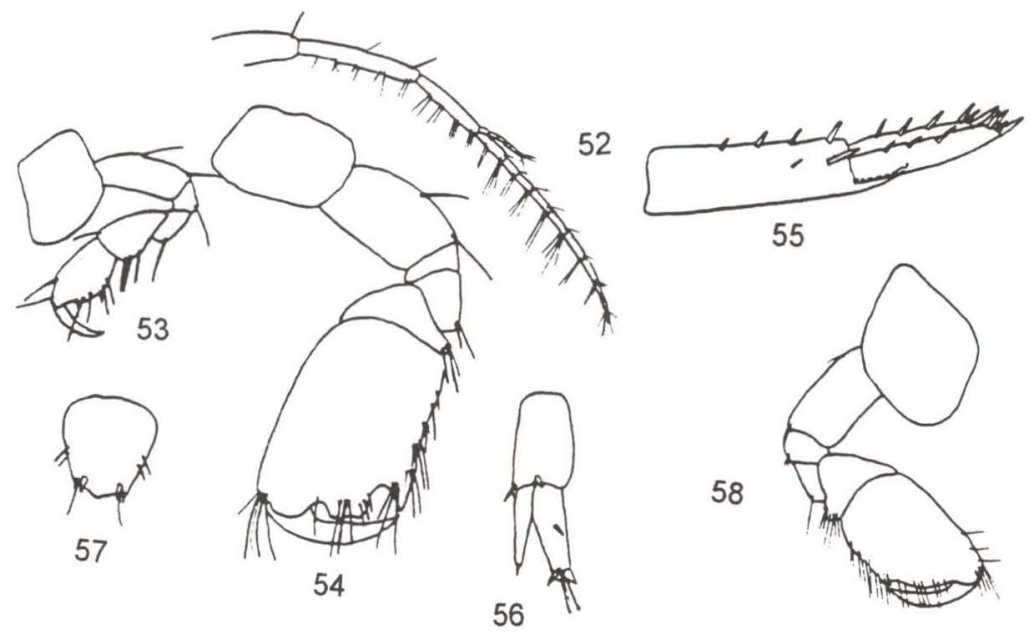

Figs 52-58. Gammaropsis (Gammaropsis) atlantica. (52-57) Macho: (52) antena 1; (53) gnatópodo 1 ; (54) gnatópodo 2; (55) urópodo 1; (56) urópodo 3; (57) telso. (58) Fêmea: gnatópodo 2.

\section{Gammaropsis (Gammaropsis) thompsoni (Walker, 1898) Figs $59-67$}

Eurystheus thompsoni Walker, 1898. Trans. Liverpool Biol. Soc. 12: 268-287. - J.L. Barnard, 1959. Occ.Pap. Allan Hancock Fdn. (21): 13-69.

Eurystheus tenuicornis Shoemaker, 1931. Proc. U.S. natn. Mus. 78 (art. 18): 1-18.

Gammaropsis thompsoni Conlan, 1983. Publ. Nat. Sci. 4: 1-75.

Diagnose do macho $(4,5 \mathrm{~mm})$. Cabeça com lobos laterais terminando em ângulo agudo. Artículo 1 do pereópodo 5 muito desenvolvido, cobrindo praticamente o artículo 2, principalmente, nos exemplares maiores. Os segmentos 4 e 5 do pleon apresentam dorsalmente um par de dentes e um par de cerdas; epímero pleonal $3 \mathrm{com}$ margem lateral convexa, e margem ventro-distal tanto deste segmento quanto do 2 com um pequeno dente seguido de uma reentrância. Gnatópodo 1 menos robusto que 


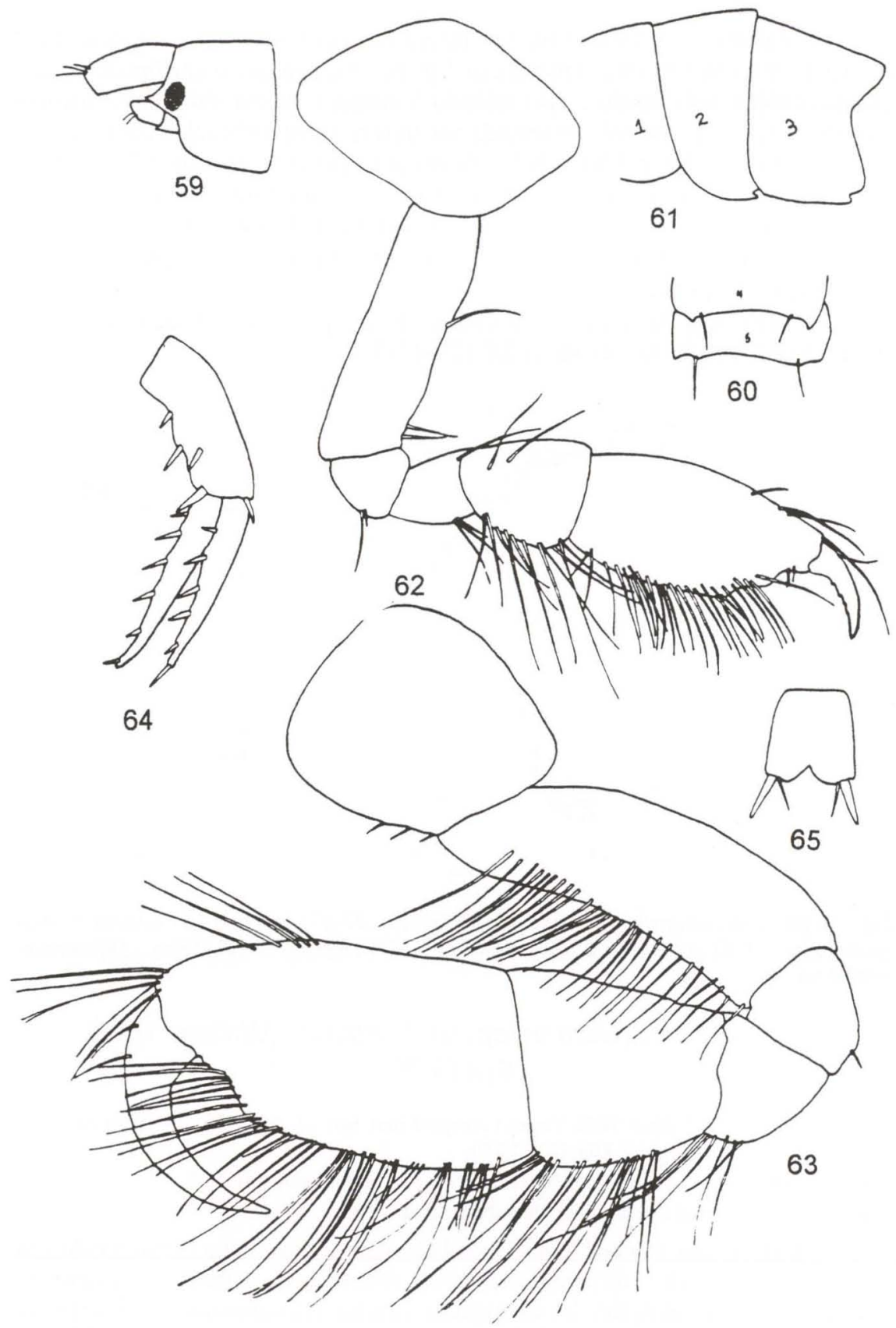

Figs 59-65. Gammaropsis (Gammaropsis) thompsoni, macho. (59) Cabeça; (60) pleonitos 4 e 5 ; (61) urossomitos 1-3; (62) gnatópodo $1 ;(63)$ gnatópodo $2 ;(64)$ urópodo $3 ;(65)$ telso. 
2, com palma oblíqua. Artículo 2 do gnatópodo 2 com uma densa fileira de cerdas em sua margem dorsal, artículo 6 maior que o 5, sem palma definida. Urópodo 3 com espinhos nas margens dos ramos e pedúnculos. Telso com uma reentrância mediana na margem distal, apresentando de cada lado, um espinho e uma cerda.

Diagnose da fêmea $(4,7 \mathrm{~mm})$. Gnatópodo 1 com artículo 7 proporcionalmente mais longo que o do macho. Gnatópodo 2 menos robusto, com artículo 2 sem a densa cerdação na margem anterior, palma oblíqua, definida por 2 espinhos.

Distribuição batimétrica e latitudinal. Nossos exemplares foram coletados em profundidades de 12 até 166 metros, em sedimento variado, entre as latitudes de $22^{\circ} 48^{\prime}-34^{\circ} 25^{\prime} \mathrm{S}$.

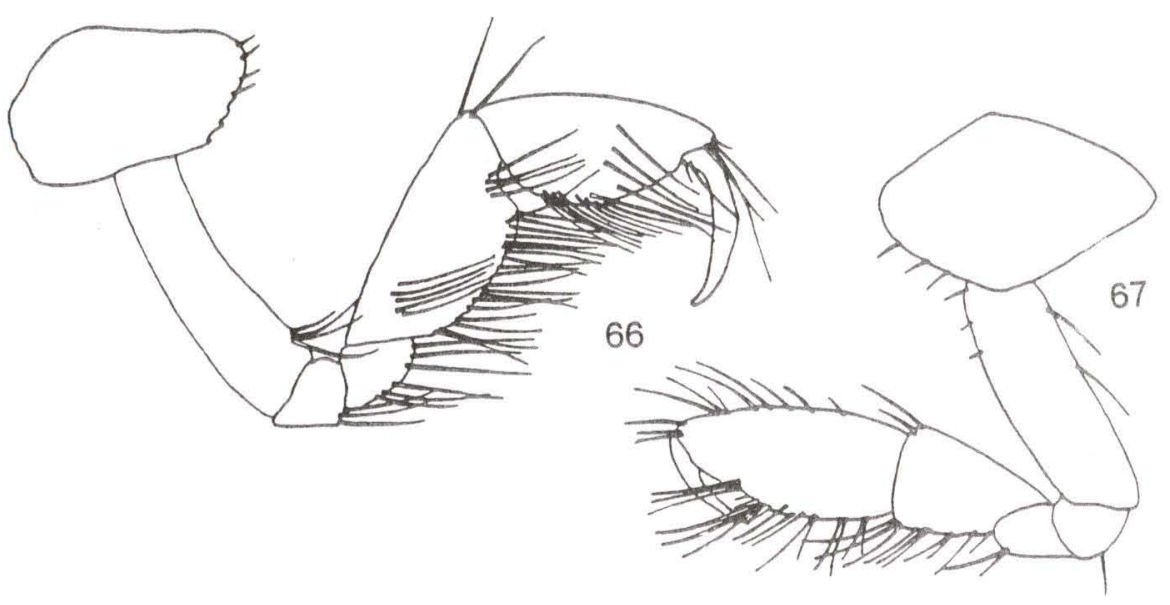

Figs 66-67. Gammaropsis (Gammaropsis) thompsoni, fêmea. (66) Gnatópodo 1; (67) gnatópodo 2 .

\section{Gammaropsis (Gammaropsis) togoensis (Schellenberg, 1925) Figs 68-72}

Eurystheus togoensis Schellenberg, 1925. Beitr. Kennt. Meeresfauna Westafr. 3 (4): 111-204. Sivaprakasam, 1968. Jour. mar. biol. Ass. India 10 (2): 283-285.

Gammaropsis togoensis; Krapp-Schieckel \& Myers, 1979. Boll. Mus. Civ. Stor. nat., Verona, 6: 441-467.

Diagnose do macho $(4,0 \mathrm{~mm})$. Cabeça com lobos laterais bastante proeminentes, olhos de tamanho médio e ovais. Antena 1 com flagelo acessório 3-articulado. Gnatópodo 1 com palma oblíqua. Gnatópodo 2 robusto e com cerdas escassas, artículo 6 de forma ovóide, palma oblíqua delimitada por uma suave projeção com 1 espinho e 3 cerdas. Urópodo 3 com ramo interno mais curto que o externo, apresentando espinhos terminais. Extremidade distal do telso com uma projeção triangular e de 1 espinho de cada lado.

Diagnose da fêmea $(3,8 \mathrm{~mm})$. Assemelha-se ao macho, diferindo apenas em relação ao gnatópodo 2 que é menos robusto, e o artículo 7 serrilhado na margem interna. Existe uma maior cerdação no artículo 6 em relação ao macho. 
Distribuição batimétrica e latitudinal. Exemplares coletados desde a região entremarés, entre algas até profundidades de 73 metros. A distribuição latitudinal é registrada entre $18^{\circ} 54^{\prime}-33^{\circ} 47^{\prime} \mathrm{S}$.

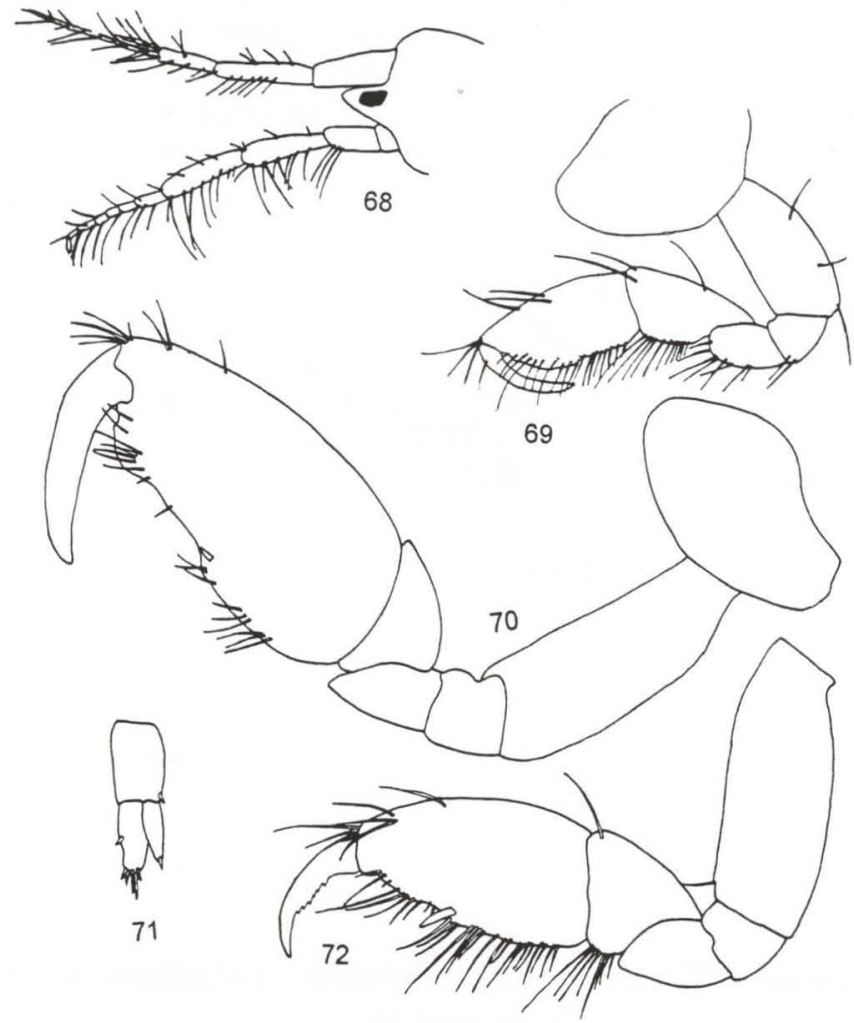

Figs 68-72. Gammaropsis (Gammaropsis) togoensis. (68-71) Macho: (68) cabeça; (69) gnatópodo 1; (70) gnatópodo 2; (71) urópodo 3. (72) Fêmea: gnatópodo 2.

\section{Gammaropsis (Podoceropsis) sophiae (Boeck, 1861)}

\section{Figs $73-78$}

Podoceropsis sophiae Boeck, 1861. Forhandl. Skand. Naturforsk Mode Kiobenhavn 8: 631-677. Chevreux \& Fage, 1925. Faune de France 9: 1-488. - Reid, 1951. Atlantide Rep. 2: 289-291. Karaman, 1973. Mem. Mus. civ. Stor. nat., Verona, 20: 99-142.

Podoceropsis pusilla Chevreux, 1925. Bull. Soc. zool. Fr. 50: 278-311.

Gammaropsis sophiae; Krapp-Shieckel \& Myers, 1979. Boll. Mus. civ. Stor. nat., Verona, 6: 441-467.

Diagnose do macho $(6,5 \mathrm{~mm})$. Cabeça com lobos laterais pouco proeminentes. Antena 1 sem flagelo acessório. Gnatópodo 1 menos desenvolvido que gnatópodo 2 , com artículo 7 com uma série de dentículos na margem interna e quase tão 
longo quanto o artículo 6. Gnatópodo 2 robusto e com poucas cerdas, artículo 6 grande, mais longo que largo, palma com 2 projeções e escavações, uma delas bem alongada que delimita a palma, artículo 7 mais curto que a palma sem serrilhação na margem interna. Urópodo 3 sem espinhos nos ramos subiguais em comprimento. Telso triangular e desprovido de espinhos e cerdas.

Diagnose da fêmea $(6,0 \mathrm{~mm})$. Difere do macho em relação à palma do gnatópodo 2, com reentrâncias e projeções pouco conspícuas.

Distribuição batimétrica e latitudinal. Nossos exemplares ocorreram entre as profundidades de 40 e 150 metros em substrato arenoso, entre as latitudes de $22^{\circ} 10^{\prime}-38^{\circ} 05^{\prime} \mathrm{S}$.

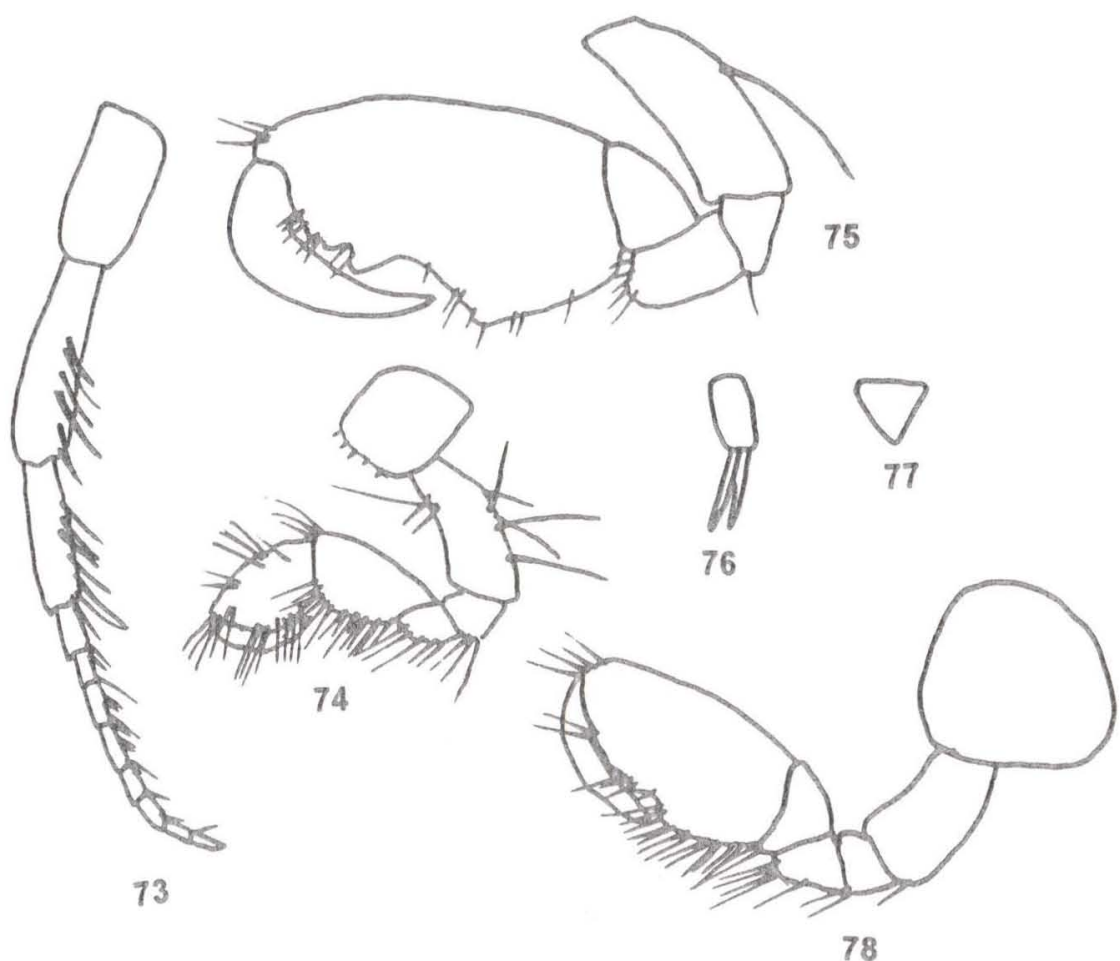

Figs 73-78. Gammaropsis (Podoceropsis) sophiae. (73-77) Macho: (73) antena 1; (74) gnatópodo 1; (75) gnatópodo 2; (76) urópodo 3; (77) telso. (78) Fêmea: gnatópodo 2.

\section{Globosolembos smithi (Holmes, 1905)}

Figs $79-85$

Autonoe smithi Holmes, 1905. Bull. U.S. Bur. Fish 24: 459-529.

Lembos smithi Stebbing, 1906. Das Tierrech 21: 1-806. - Myers, 1981. Mem. Hourglass Cruis. 5 (part 5): 1-75.

Globosolembos smithi; Myers, 1988. Crustaceana (Suppl. 13): 167-192. 
Diagnose do macho (4,0mm). Flagelo acessório 6-articulado. Segmento pereonal 2 com processo esternal pontiagudo. Gnatópodo 1 mais robusto que o gnatópodo 2, com artículo 2 de aparência robusta, artículo 5 menor que o 6 , sendo este massivo aproximadamente $2 / 3$ mais longo que largo; palma sinuosa, definida por um espinho; artículo $7 \mathrm{com}$ uma fileira de espinhos na margem interna. Gnatópodo $2 \mathrm{com}$ artículos 5 e 6 apresentando margens dorsais e ventrais dorsalmente cerdosas; palma transversa. Urópodo 3 com ramos maiores que o pedúnculo, com longas cerdas terminais. Telso com margem distal apresentando, de cada lado, uma pequena projeção com um tufo de 3 cerdas.

Diagnose da fềmea $(5,6 \mathrm{~mm})$. Difere do macho basicamente em relação ao artículo 6 do gnatópodo 2 que é um pouco mais longo.

Distribuição batimétrica e latitudinal. Na costa brasileira foi registrada desde a região entremarés até a profundidade de 140 metros, em substrato arenoso. Sua distribuição latitudinal foi de $13^{\circ}-23^{\circ} 25^{\prime} \mathrm{S}$.

\section{Lembos hypacanthus K.H. Barnard, 1916}

Figs $86-90$

Lembos hypacanthus K.H. Barnard, 1916. Ann. S. Afr. Mus. 15: 105-302. - Schellenberg, 1925. Beitr.

Kennt. Meeresfauna Westafr. 3 (4): 11-204.

Diagnose do macho. (3,5mm) Cabeça com lobos laterais pouco proeminentes, flagelo acessório 3-articulado. Gnatópodo 1 mais robusto que o gnatópodo 2, artículos 5 e 6 cerdosos nas duas margens, palma ligeiramente oblíqua, definida por 1 espinho e com uma projeção triangular. Gnatópodo 2 simples de aparência delgada, artículo 5 com cerdas plumosas nas margens ventrais, pouco mais largo que o 6, que apresenta cerdação em ambas as margens. Urópodo $3 \mathrm{com}$ ramos subiguais em comprimento, maiores que o pedúnculo, ramo interno com espinhos na margem externa e terminais, ramo externo com cerdas terminais. Telso com margem distal com 1 par de espinhos e cerdas.

Diagnose da fêmea $(4,0 \mathrm{~mm})$. Difere do macho principalmente em relação ao gnatópodo 1 pois apresenta palma suavemente obliqua definida por um espinho, sem cerdação tão evidente nos artículos 5 e 6 , sendo este último proporcionalmente mais longo que largo quando comparado ao do macho. Gnatópodo 2 com padrão de cerdação diferente em relação ao macho.

Distribuição batimétrica e latitudinal. Exemplares coletados em região entremarés, entre algas, na latitude de $20^{\circ} 19^{\prime} \mathrm{S}$.

\section{Chave para as espécies do gênero Photis}

1. Cabeça com lobos laterais pouco proeminentes; palma do gnatópodo 2 do macho com escavação profunda (Fig. 92); ramo externo do urópodo 3 com cerdas nas margens (Fig. 94) ...................... brevipes

- . Cabeça com lobos laterais projetados; palma do gnatópodo 2 do macho sem escavação profunda (Fig. 100); urópodo 3 com ramo externo sem cerdas nas margens (Fig. 101) 


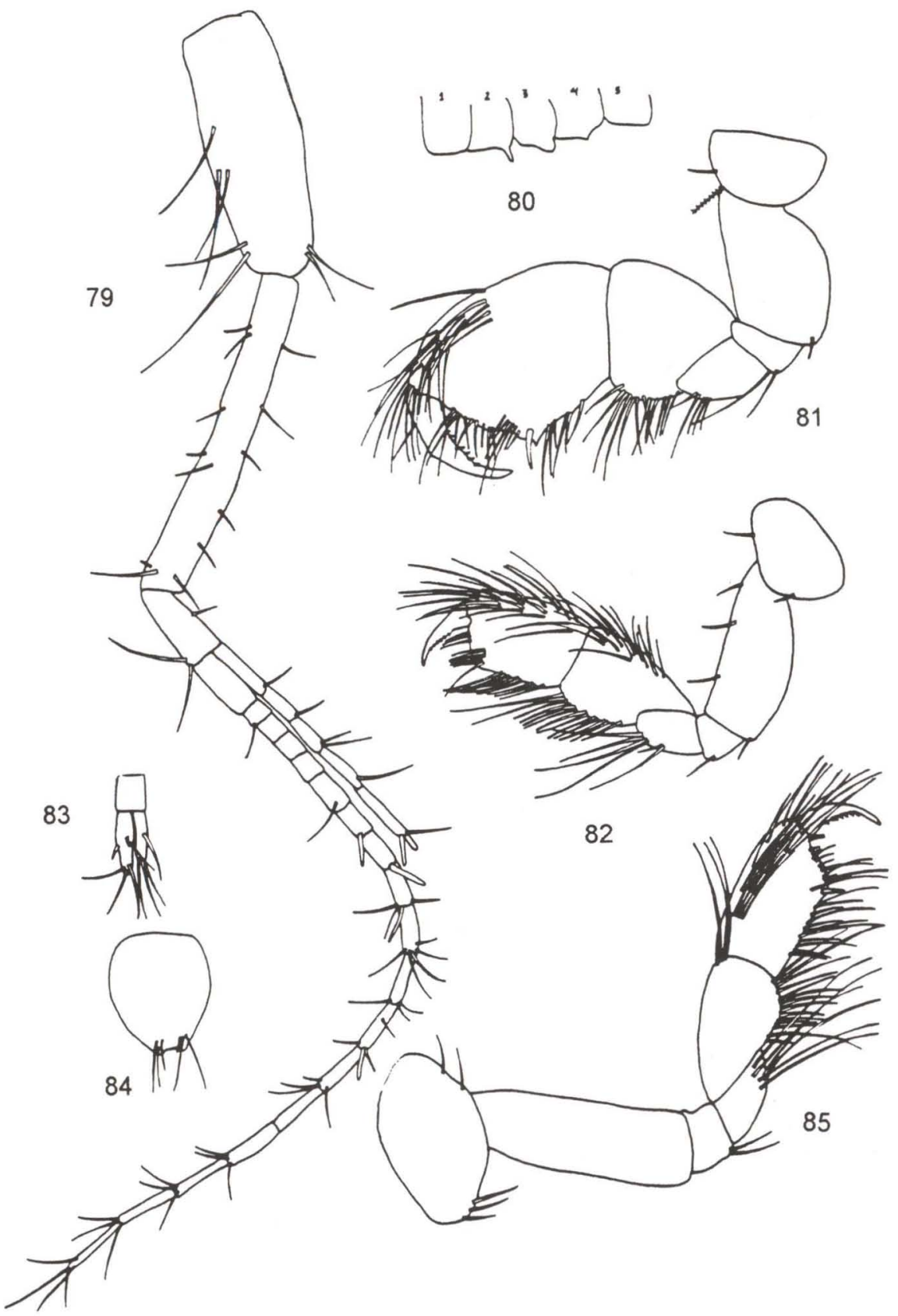

Figs 79-85. Globosolembos smithi. (79-84) Macho: (79) antena $1 ;(80)$ pereonitos $1-5 ;(81)$ gnatópodo 1; (82) gnatópodo 2; (83) urópodo 3; (84) telso. (85) Fêmea: gnatópodo 2. 


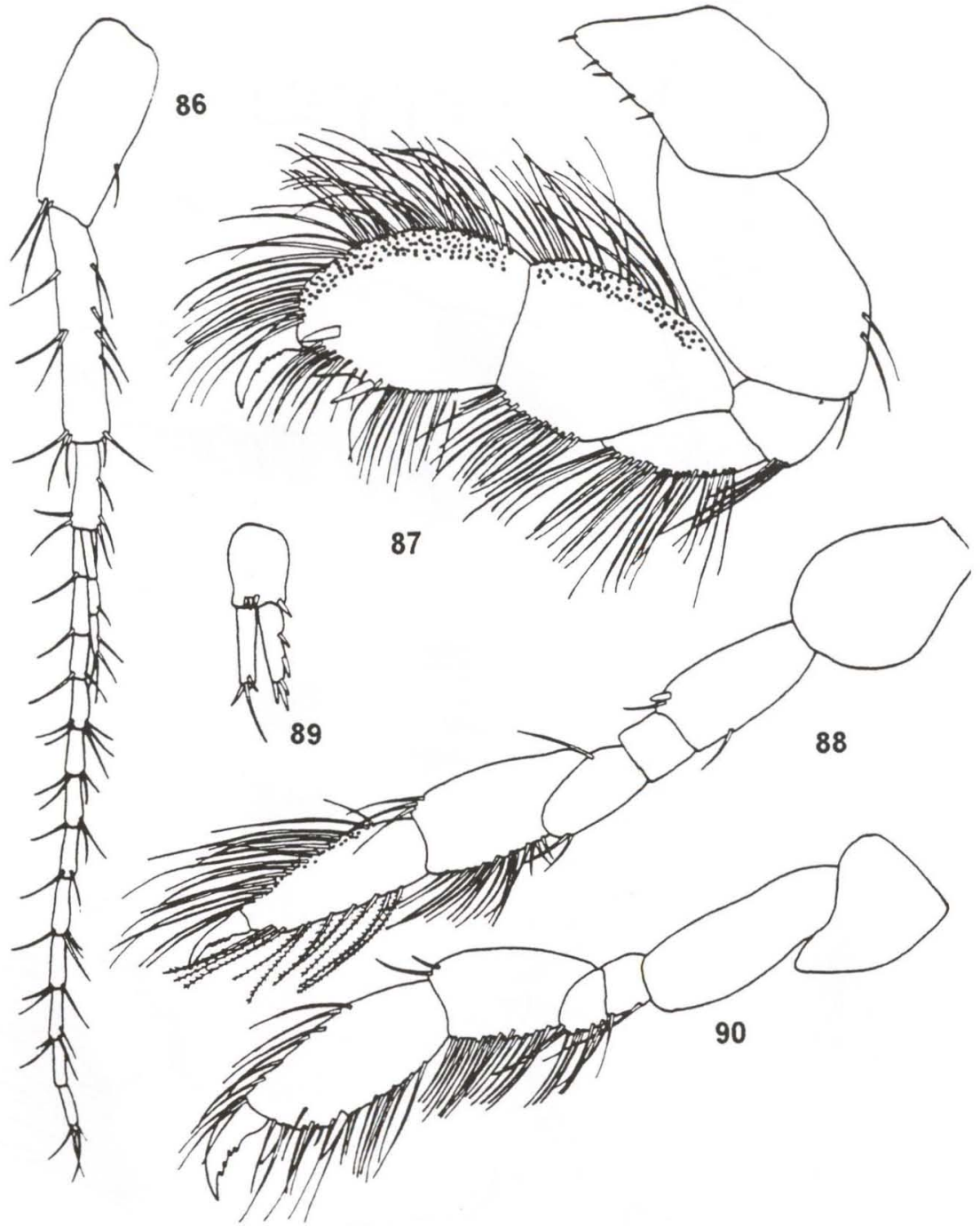

Figs 86-90. Lembos hypacanthus. (86-89) Macho: (86) antena $1 ;(87)$ gnatópodo $1 ;(88)$ gnatópodo 2; (89) urópodo 3. (90) Fêmea: gnatópodo 1.

\section{Photis brevipes Shoemaker, 1942}

Figs 91-97

Photis brevipes Shoemaker, 1942. Smiths. Misc. Coll. 101 (11): 1-52. - Conlan, 1983. Publ. Nat. Sci. 4:1-75.

Photis california J.L. Barnard, 1954. Ore. St. Monogr. Stud. Zool. 8: 1-103.

Diagnose do macho $(4,0 \mathrm{~mm})$. Cabeça com lobos laterais pouco proeminentes, olhos pequenos. Sem flagelo acessório. Gnatópodo 1 com palma oblíqua, 


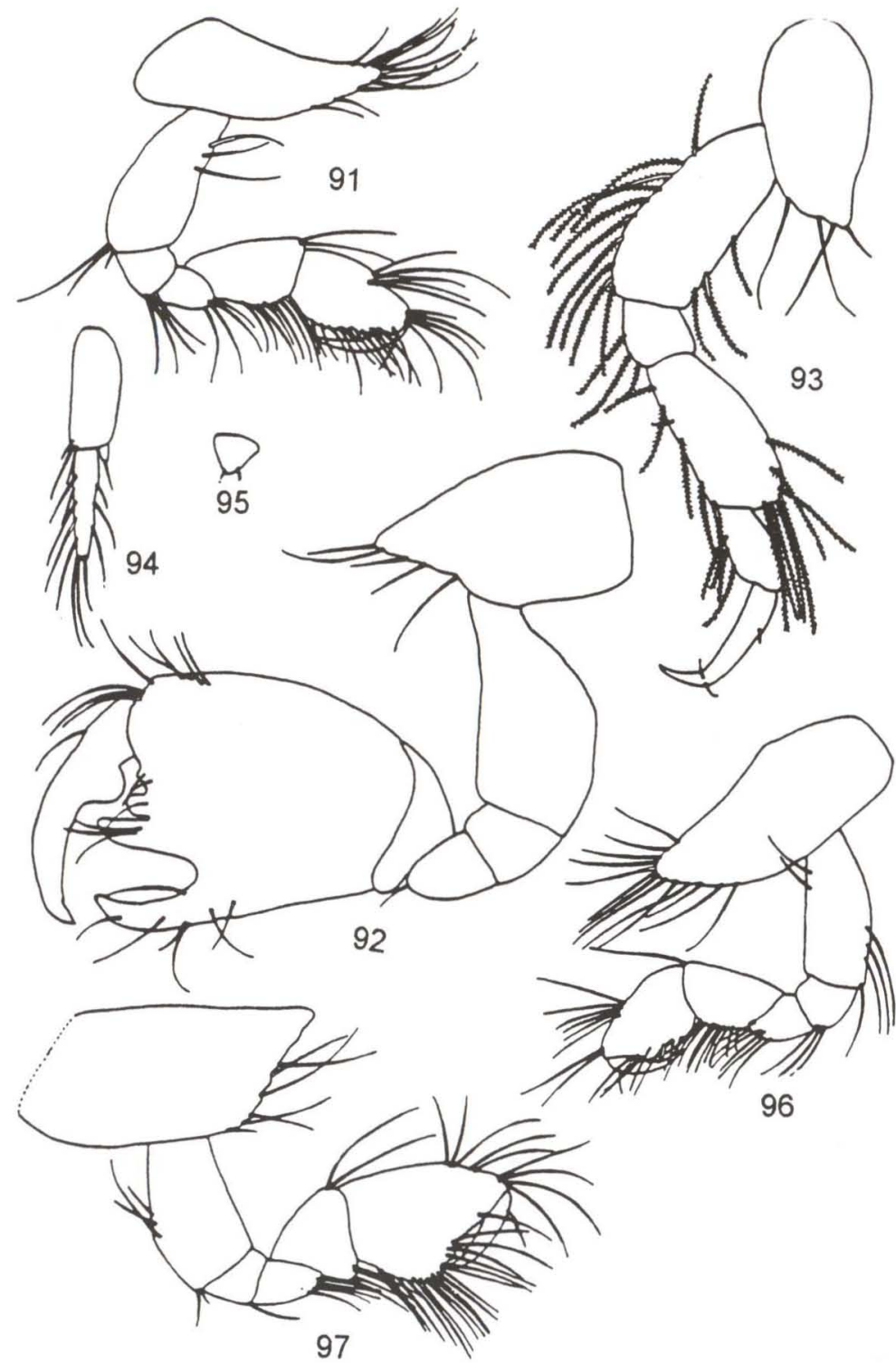

Figs 91-97. Photis brevipes. (91-95) Macho: (91) gnatópodo 1 ; (92) gnatópodo 2; (93) pereópodo 1; (94) urópodo 3; (95) telso. (96-97) Fêmea: (96) gnatópodo 1; (97) gnatópodo 2.

armada com um espinho na porção mediana. Gnatópodo 2 com palma transversa definida por um grande dente seguido por uma escavação profunda e mais dois dentes, artículo 7 com projeção arredondada na margem interna. Pereópodos 1 e 2 com cerdas plumosas. Urópodo 3 com ramo externo apresentando cerdas em ambas as margens. Telso triangular e minúsculo. 


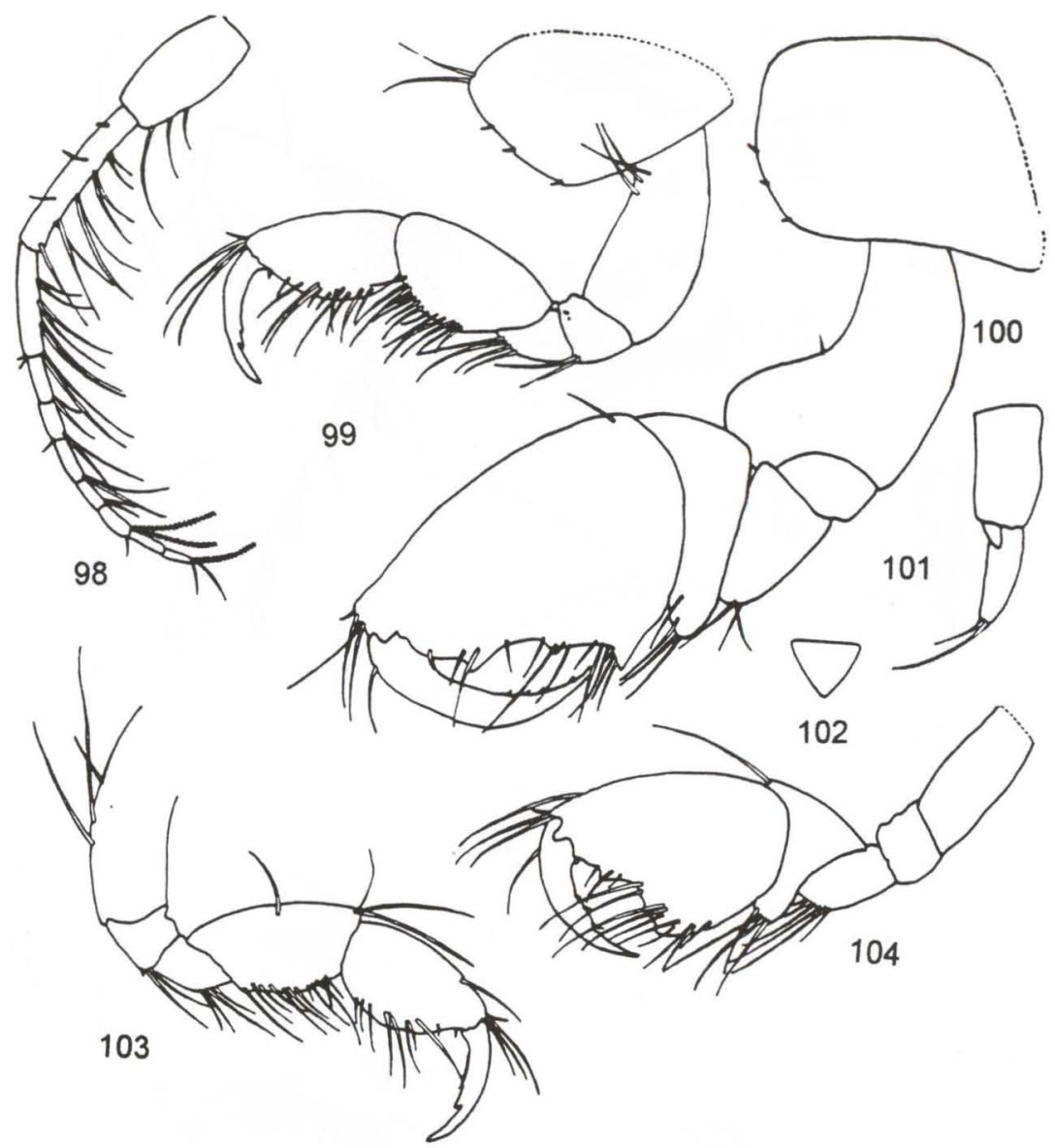

Figs 98-104. Photis longicaudata. (98-102) Macho: (98) antena 1; (99) gnatópodo 1; (100) gnatópodo 2; (101) urópodo 3; (102) telso. (103-104) Fêmea: (103) gnatópodo 1; (104) gnatópodo 2 .

Diagnose da fêmea (4,0mm). Diferencia-se do macho, principalmente, quanto aos gnatópodos que são menos robustos. Palma do gnatópodo 1 bastante oblíqua, com 1 espinho. Palma do gnatópodo 2 ligeiramente escavada e crenulada.

Distribuição batimétrica e latitudinal. Espécie com ampla distribuição batimétrica (desde a região entremarés até 117 metros), em substratos arenoso e lodoso. Distribuição entre as latitudes $18^{\circ} 44^{\prime}-33^{\circ} 58^{\prime}$ 'S.

\section{Photis longicaudata Bate \& Westwood, 1862}

Figs $98-104$

Photis longicaudata Bate \& Westwood, 1862. A History of British sessile-eyed Crustacea, London, John van Voarst, 2 vol. - Ledoyer, 1967. Recl. Trav. St. mar. Endoume (Suppl. 4): 7-56. Hirayama, 1984. Publs Seto mar. biol. Lab. 29 (1/3): 1-92. 
Diagnose do macho $(4,0 \mathrm{~mm})$. Cabeça com lobos laterais projetados. Sem flagelo acessório. Gnatópodo 1 com artículo 5 pouco mais longo que o artículo 6; palma oblíqua; artículo 7 serrilhado na margem interna. Gnatópodo 2 com artículo 2 apresentando um lobo arredondado na margem dorso-distal, palma apresentando escavações e projeções, uma das quais delimitando a palma; artículo 7 com espinhos na margem interna. Urópodo $3 \mathrm{com}$ ramo externo menor que o pedúnculo, com 2 longas cerdas terminais. Telso pequeno e triangular.

Diagnose da fêmea $(3,1 \mathrm{~mm})$. Gnatópodo 2 menor, palma também com projeções e escavações, mas menos marcantes que no macho.

Distribuição batimétrica e latitudinal. Também apresenta ampla distribuição batimétrica (desde a zona entremarés até 117 metros), em substrato sedimentar. Também tem ampla distribuição latitudinal na costa brasileira $\left(7^{\circ} 45^{\prime}-34^{\circ} 32^{\prime} \mathrm{S}\right)$.

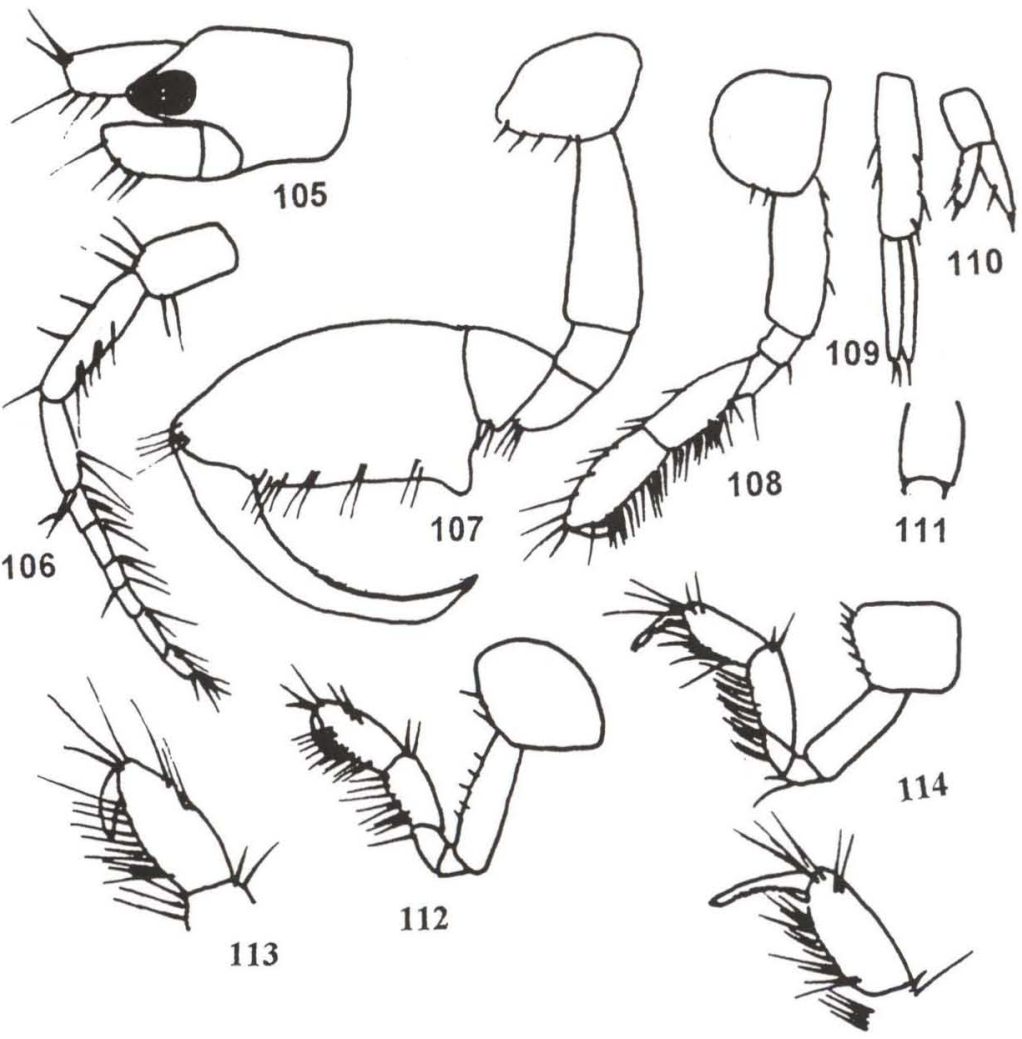

115

Figs 105-115. Pseudomegamphopus barnardi. (105-111) Macho: (105) cabeça; (106) antena 1; (107) gnatópodo 1; (108) gnatópodo 2; (109) urópodo 1; (110) urópodo 3; (111) telso. (112-115) Fêmea: (112) gnatópodo 1; (113) detalhe da palma do gnatópodo 1; (114) gnatópodo 2 ; (115) detalhe da palma do gnatópodo 2. 


\section{Pseudomegamphopus barnardi Myers, 1968 Figs 105-115}

Pseudomegamphopus barnardi Myers, 1968. Jour. Linn. Soc. Zool. 47 (313): 527-531.

Diagnose do macho $(3,6 \mathrm{~mm})$. Cabeça com lobos laterais fortemente pronunciados. Flagelo acessório muito reduzido, 2-articulado, sendo o artículo 2 rudimentar. Gnatópodo 1 maior que o 2, com artículo 5 reduzido e artículo 6 massivo e mais longo que largo, palma com uma protuberância proximal; artículo 7 longo e encurvado. Gnatópodo 2 delgado e menor do que o gnatópodo 1; artículos 5 e 6 alongados; palma oblíqua. Urópodo 3 com pedúnculo e ramos curtos, subiguais em comprimento. Telso com 2 espinhos na margem distal, um em cada extremidade.

Diagnose da fêmea $(3,7 \mathrm{~mm})$. Gnatópodo 1 delgado, com artículo 5 e 6 subiguais, palma serrilhada e definida por um espinho. Gnatópodo 2 com palma oblíqua.

Distribuição batimétrica e latitudinal. Exemplares coletados entre as profundidades de 56 e 150 metros, em substrato de cálcareo e cascalho. Exemplares coletados entre as latitudes de $21^{\circ} 42^{\prime}-34^{\circ} 34^{\prime} \mathrm{S}$.

\section{REFERÊNCIAS BIBLIOGRÁFICAS}

Barnard, J.L. 1973. Revision of corophiid and related families (Amphipoda). Smiths. Contr. Zool. 151: 1-27.

Barnard, J.L. \& G.S. Karaman. 1991. The Families and Genera of Marine Gammaridean Amphipoda (Except Marine Gammariods). Rec. Austral. Mus. 1/2 (Suppl. 13): 1-866.

Barnard, J.L. \& J.D. Thomas. 1988a. Vadosiapus copacapamus, anew genus and species of Exoedicerotidae from Brazil (Crustacea-Amphipoda). Proc. biol. Soc. Wash. 101 (2): 366-374

-1988b. Ipanemidae, new family, Ipanema talpa, new genus and species from the surf zone of Brazil (Amphipoda: Gammaridea: Haustoroidea). Proc. Biol. Soc. Wash. 101 (3): 614-621.

Myers, A.A. 1981. Amphipod Crustacea. I Family Aoridae. Mem. Hourglass Cruis. 5 (5): 1-73.

OLIVEIRA, L.P.H. 1951. The genus Elasmopus on the coast of Brasil with descripitions of Elasmopus bernardi n.sp. and E. fusimanis n.sp. (Crustacea, Amphipoda). Bolm. Inst. Paul. Oceanogr. 2 (2): $1-17$.

1953. Crustacea Amphipoda do Rio de Janeiro. Mem. Inst. Oswaldo Cruz 51: 289-376.

1954. Nova espécie de crustácea Amphipoda da Baia de Guanabara: Ampelisca soleata.

Mem. Inst. Oswaldo Cruz 52 (3/4): 603-615.

1955. Phoxocephalus capuciatus, nova espécie de crustácea Amphipoda, Phoxocephalidae.

Mem. Inst. Oswaldo Cruz 53: 313-317.

SEREJo, C. 1995 Podocerus fissipes n.sp. a new species of sponge dwelling amphipod (Amphipoda Podoceridae) from the Brazilian Coast. Nauplius, Rio Grande, 3: 49-57.

1997. Hemiaegina costai Quitete, 1972, a synonym of Hemiaegina minuta Mayer, 1890 (Amphipoda, Caprellidae). Crustaceana 70 (5): 630-632.

WAKabarA, Y. \& F.P.P. LeIte. 1977. Heterophlias seclusus Shoemaker, 1933. (Amphipoda Philiantidae) from the Brazilian coast. Crustaceana 33: 90-96.

Wakabara, Y.; A.S. Tararam; M.T. Valério-Berardo \& F.P. Pereira Leite. 1988. Liljeborgiidae (Amphipoda, Gmmaridea) from the Southeastern coast of Brazil. Rel. Int. Inst. Oceanogr. Univ. São Paulo 30: 1-9.

WaKabara, Y.; A.S. Tararam; M.T. Valério-Berardo; W. Duleba \& F.P. Pereira-Leite. 1991. Gammaridean and Caprellidean fauna from Brazil. Hydrobiologia 223: 69-77.

Recebido em 29.X.1998; aceito em 05.V.2000

Revta bras. Zool. 17 (2): 481 - 504, 2000 